\title{
Predicting the quench sensitivity of Al-Zn-Mg-Cu alloys: A model for linear cooling and strengthening
}

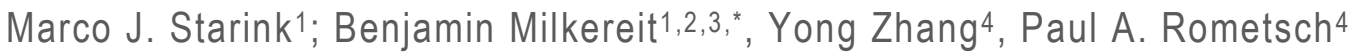 \\ ${ }^{1}$ Materials Research Group, Faculty of Engineering and the Environment, University of \\ Southampton, S017 1BJ Southampton, United Kingdom \\ ${ }^{2}$ Chair of Materials Science, Faculty of Marine Technology and Mechanical Engineering, \\ University of Rostock, 18051 Rostock, Germany \\ ${ }^{3}$ Polymer Physics Group, Institute of Physics, University of Rostock, 18051 Rostock, \\ Germany \\ ${ }^{4}$ Department of Materials Science and Engineering, Monash University, \\ Clayton, VIC 3800, Australia
}

corresponding author: Benjamin Milkereit, benjamin.milkereit@uni-rostock.de

\section{Abstract}

In this work the quench sensitivity of Al-Zn-Mg-Cu alloys is studied through continuous cooling at constant rates of a range of alloys using differential scanning calorimetry (DSC), transmission electron microscopy (TEM), scanning electron microscopy (SEM) and hardness testing. The DSC, TEM and SEM data show that the cooling reactions are dominated by a high temperature reaction (typically $\sim 450{ }^{\circ} \mathrm{C}$ down to $\sim 350^{\circ} \mathrm{C}$ ) due mostly to $\mathrm{S}-\mathrm{Al}_{2} \mathrm{CuMg}$ phase formation, a medium temperature reaction $\left(\sim 350^{\circ} \mathrm{C}\right.$ down to $\left.\sim 250{ }^{\circ} \mathrm{C}\right)$ due predominantly to $\eta-\mathrm{Mg}(\mathrm{Al}, \mathrm{Cu}, \mathrm{Zn})_{2}$ phase formation and a lower temperature reaction $\left(250^{\circ} \mathrm{C}\right.$ down to $\left.\sim 150^{\circ} \mathrm{C}\right)$ due to a $\mathrm{Zn}$-Cu rich thin plate phase. A new, physically-based model is constructed to predict rates of all reactions, enthalpy changes and resulting yield strength in the artificially aged condition. The model incorporates a recently derived model for diffusion-controlled reactions based on the extended volume fraction concept as well as recent findings from first principles modelling of enthalpies of the relevant phases. The model shows a near perfect correspondence with data on all 6 alloys studied extensively by cooling DSC and hardness testing, and 
allows prediction of the influence of the 3 major elements and 3 dispersoid forming elements on quench sensitivity.

\section{Graphical abstract}
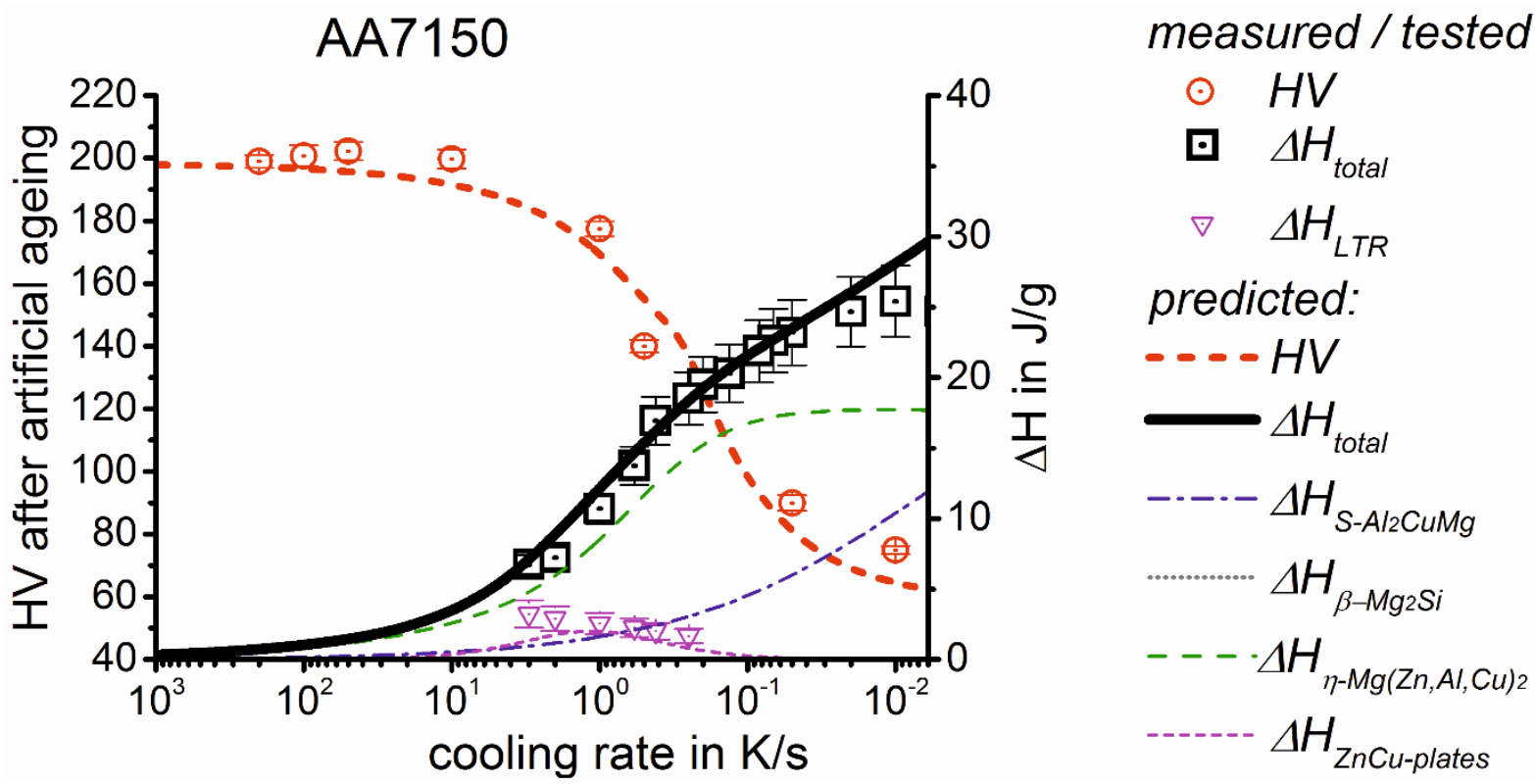

\section{Highlights}

- New accurate model for continuous cooling quench sensitivity of Al-Zn-Mg-Cu alloys

- Model considers four phases: $\mathrm{S}-\mathrm{Al}_{2} \mathrm{CuMg}, \beta-\mathrm{Mg}_{2} \mathrm{Si}, \mathrm{n}-\mathrm{Mg}(\mathrm{Al}, \mathrm{Cu}, \mathrm{Zn})_{2} \& \mathrm{Zn}-\mathrm{Cu}$ plate phase

- Successfully tested on enthalpy changes and hardness of six alloys

- Model is verified on an extensive set of DSC, SEM, TEM and hardness experiments

- Model predicts influence of 3 major \& 3 dispersoid forming elements

\section{Keywords}

Al-Zn-Mg-Cu alloys, quench sensitivity, Differential Scanning Calorimetry (DSC), precipitation kinetics, modelling

\section{Introduction}

In processing of high strength aluminium alloys, such as the Al-Zn-Mg and Al-Li-Cu based alloys, the quenching is a crucial stage. This is due to the formation of precipitates during (relatively) slow 
quenching which are generally detrimental to properties such as toughness, stress corrosion cracking resistance and yield strength (e.g. [1]). Slow quenching decreases the amount of solute that is available in the matrix for subsequent age-hardening due to the formation of coarse, non-hardening quenchinduced precipitates. This results in a reduction of the final mechanical properties, which is crucial to the application and can be the main limiting factor in application of the high strength alloy. Precipitation on defects such as grain boundaries during quenching is in practice nearly unavoidable for all high strength aluminium alloys, and the quench sensitivity generally increases with increasing content of main alloying elements. Also the minor alloying elements $\mathrm{Zr}, \mathrm{Mn}$ and $\mathrm{Cr}$, which form intermetallic particles of sizes typically in the range of $10-100 \mathrm{~nm}$ (generally termed 'dispersoids'), strongly influence the quench sensitivity as those dispersoids may act as nucleation sites for the quench-induced phase. The latter particularly holds for incoherent dispersoids, whereby the dispersoids typically lose their coherence by recrystallization (e.g. [2,3]). Hence, also the degree of recrystallisation affects the quench sensitivity. Although there are some models available, which allow fitting of multi parameter approximations to fit quenching rate data of single alloys, no model is available in the literature that predicts composition dependency.

The aim of this work is to derive and validate a model for quench induced precipitation and the resulting yield strength in age hardened condition for Al-Zn-Mg (7xxx) alloys. These 7xxx series alloys are used widely in the aerospace industry (e.g. [4]), which is still heavily reliant on these alloys due to their desirable strength-to-weight-to-cost ratios. The addition of $\mathrm{Cu}$ to the ternary Al-Zn-Mg system, together with small amounts of $\mathrm{Cr}, \mathrm{Mn}$ and/or $\mathrm{Zr}$, has resulted in the highest strength aluminium alloys available, with the yield strengths of some 7xxx alloys reaching more than $600 \mathrm{MPa}$ [1].

In the new model we want to particularly include recent improved models for diffusion-controlled reactions $[5,6]$, the advances in modelling of the thermodynamics of complex alloy systems, including first principles modelling of phases in the present alloys [7] and the computationally efficient schemes for integrating these components as recently introduced by the present authors [8]. For the validation of the model, we will use a range of experimental techniques covering the microstructure on a range of 
length scales, the thermodynamics of the reactions and the resulting mechanical properties. This includes transmission electron microscopy (TEM), high resolution TEM (HRTEM), scanning electron microscopy (SEM), and high resolution fast and slow differential scanning calorimetry (DSC) covering cooling rates from $0.005 \mathrm{~K} / \mathrm{s}$ to $5 \mathrm{~K} / \mathrm{s}$.

\section{Experimental}

\subsection{Investigated alloys and their thermomechanical treatments}

In total $12 \mathrm{Al-Zn-Mg(-Cu-Si)} \mathrm{alloys} \mathrm{covering} \mathrm{a} \mathrm{wide} \mathrm{range} \mathrm{of} \mathrm{compositions} \mathrm{were} \mathrm{investigated} \mathrm{from}$ which 6 alloys were selected for extensive continuous cooling experiments. The chemical compositions of these alloys as well as an overview of the performed experiments are given in Table 1. (All compositions in this work are in at $\%$ and composition ratios are based on at $\%$.)

Table 1: Chemical compositions of investigated alloys (in atomic \%), with experiments performed. The alloys are termed according to the nominal or nearest AA standard of common 7xxx alloys, C refers to a commercially produced alloy, $m$ stands for composition close to medium of alloy standard. $c D S C=$ cooling DSC, hDSC $=$ heating DSC

\begin{tabular}{llllllllll}
\hline Alloys & $\mathrm{Si}$ & $\mathrm{Fe}$ & $\mathrm{Zn}$ & $\mathrm{Mg}$ & $\mathrm{Cu}$ & $\mathrm{Cr}$ & $\mathrm{Mn}$ & $\mathrm{Zr}$ & Experiments \\
\hline AA7150cm & 0.02 & 0.03 & 2.74 & 2.51 & 0.91 & - & 0.02 & 0.04 & TEM, cDSC, SEM, HV, OM, EBSD \\
AA7055m & 0.03 & 0.02 & 3.56 & 2.36 & 0.90 & - & - & 0.04 & cDSC, OM, SEM, HV \\
AA7085C & 0.07 & 0.02 & 3.58 & 1.72 & 0.93 & - & - & 0.04 & cDSC, OM, SEM, HV \\
AA7085lowCu & 0.12 & 0.01 & 3.40 & 1.60 & 0.41 & - & - & 0.04 & cDSC, OM, SEM, HV \\
AA7020 & 0.11 & 0.08 & 1.85 & 1.36 & 0.02 & 0.06 & 0.06 & 0.04 & TEM, cDSC, SEM, OM, HV \\
AA7049Ac & 0.26 & 0.18 & 3.60 & 3.43 & 0.86 & 0.12 & 0.10 & - & cDSC, OM, SEM, HV \\
AA7449C & 0.03 & 0.02 & 3.4 & 2.3 & 0.74 & - & - & 0.05 & hDSC, TS, SEM, TEM, OM \\
AA7150m & 0.03 & 0.02 & 2.61 & 2.65 & 0.84 & - & - & 0.04 & hDSC, OM \\
AA7150hiZn & 0.03 & 0.02 & 2.87 & 2.19 & 0.84 & - & - & 0.04 & hDSC \\
AA7150loCu & 0.03 & 0.02 & 2.61 & 2.65 & 0.53 & - & - & 0.04 & hDSC \\
AA7150hiCu & 0.03 & 0.02 & 2.61 & 2.65 & 1.1 & - & - & 0.04 & hDSC, SEM, OM \\
AA7150hiznCu & 0.03 & 0.02 & 2.91 & 2.2 & 1.1 & - & - & 0.04 & hDSC
\end{tabular}

The AA7020 alloy is a laboratory extruded $30 \mathrm{~mm}$ diameter rod, whilst the AA7049Ac is a commercially extruded $50 \mathrm{~mm}$ diameter rod. The AA7150c and AA7449c alloys are commercially 
processed hot-rolled plates of 80 and $30 \mathrm{~mm}$ thickness, respectively. (The code c for commercial is added to distinguish them from laboratory-produced materials.) The other alloys are hot rolled plates produced in labs. The AA7020 and AA7049A extrusions have a uniform grain structure, with a grain size of $\sim 10 \mu \mathrm{m}$; the centre of the commercially processed AA7150 plate is about $5 \%$ recrystallized, the AA7449 alloy is about $20 \%$ recrystallised and the lab produced plates are typically $50 \%$ recrystallized. These differences in recrystallization are primarily due to subtly different homogenisation and thermomechanical processing $[9,10]$. The AA7020, AA7150C, AA7055, AA7085C, AA7085lowCu and AA7049A alloys were selected for detailed quenching studies using cooling DSC (CDSC) to record the enthalpy changes in situ during cooling at a wide range of cooling rates. The remaining 6 alloys were used for a range of additional experiments to verify the model parameters and the strengthening model in water-quenched and subsequently aged conditions. Compositions and an overview of the experiments conducted are presented in Table 1. The alloys were cooled using a range of cooling rates/procedures and subsequently aged at $120^{\circ} \mathrm{C}$ for $24 \mathrm{~h}$.

\subsection{Calorimetry}

In all DSC work a pure aluminium sample of mass and size comparable to the $7 \mathrm{xxx}$ sample is used as a reference material. A baseline using pure Al samples in both microfurnaces was determined immediately prior to or after each sample measurement. Cooling differential scanning calorimetry (cDSC), covering cooling rates from $0.005 \mathrm{~K} / \mathrm{s}$ to $5 \mathrm{~K} / \mathrm{s}$, were performed employing three different devices: a Setaram 121 DSC $0.005-0.1 \mathrm{~K} / \mathrm{s}$; a Mettler-Toledo 823 DSC 0.1-0.5 K/s; a PerkinElmer Pyris 1 DSC $0.5-5 \mathrm{~K} / \mathrm{s}$. The specific precipitation enthalpy was evaluated by integrating the excess specific heat capacity curves and the relative contributions due to partially overlapping precipitation peaks were estimated using the minimum heat flow. (For further details on CDSC procedures and samples see $[11,12])$. Heating DSC (hDSC) experiments on solution treated and water-quenched samples of the laboratory produced AA7150 variant alloys were performed in a Shimadzu DSC-50 (cylindrical disc sample $\approx \varnothing 5 \times 1 \mathrm{~mm} ; \approx 60 \mathrm{mg})$ using a scanning rate of $10 \mathrm{~K} / \mathrm{min}(\approx 0.17 \mathrm{~K} / \mathrm{s})$. 


\subsection{Mechanical testing}

Vickers hardness testing was performed on both as-quenched/cooled and artificially aged samples using a $5 \mathrm{~kg}$ load. Each hardness value reported is an average based on 6 indentations made on each sample. To achieve controlled cooling rates faster than $3 \mathrm{~K} / \mathrm{s}$ a quenching dilatometer Baehr 805 was used. Tensile tests on the AA7449C alloy were carried out according to the ASTM standard E-8 with specimens tested in the $L$ (longitudinal) direction.

\subsection{SEM and EBSD}

For SEM, samples were ground and polished with SiC paper, diamond paste and colloidal silica for examination in either a JEOL JSM-6400 or a JEOL JSM-7001F field emission gun scanning electron microscope (FEG-SEM), both equipped with an energy dispersive X-ray spectrometry (EDS) system. Unless otherwise noted, imaging was conducted in the backscattered electron imaging (BEI) mode.

Electron backscatter diffraction (EBSD) was performed on selected alloys using a JEOL JSM-7001F or a JSM 6500F SEM each equipped with an HKL-Channel 5 EBSD detector and software package (Oxford, Instruments, UK). The EBSD specimens were ground and polished and subsequently electropolished using a solution of $33 \% \mathrm{HNO}$ and $67 \%$ methanol at a temperature of $-30^{\circ} \mathrm{C}$. The step size was 1 or $2 \mu \mathrm{m}$. The success rate of identification of Kikuchi patterns was $80-90 \%$.

\subsection{TEM and STEM}

TEM foils were prepared by electro-polishing with a solution of $33 \%$ nitric acid and $67 \%$ methanol, at a temperature of $-30^{\circ} \mathrm{C}$. Conventional bright field (BF) TEM was carried out on a Tecnai T20, operating at $200 \mathrm{kV}$. Elemental mapping was carried out by scanning transmission electron microscopy (STEM) based EDS imaging on a JEOL 2100F operated at 200kV.

Atomic resolution HAADF-STEM was performed on a dual aberration corrected (STEM \& TEM) FEI Titan3 microscope operated at $300 \mathrm{kV}$. A convergence angle of $15 \mathrm{mrad}$ was employed, leading to a diffraction limited (Gaussian) probe diameter of $\sim 0.12 \mathrm{~nm}$. Images were collected on a Fischione HAADF detector. 


\section{DSC cooling curves and microstructure of selected quench states}

In this section we will present new detailed cooling DSC studies and will give an overview about the main quench-induced precipitation reactions. To complement the microstructure data on a range of alloys available in the literature [2,9,13-17], therefore also results of microstructural studies on selected samples in different cooling conditions are presented.

\section{A) cooling AA7055 from $480^{\circ} \mathrm{C} 1 \mathrm{~h}$}

$\begin{array}{cllllllll}\text { mass fraction } & \mathrm{Fe} & \mathrm{Si} & \mathrm{Zn} & \mathrm{Mg} & \mathrm{Cu} & \mathrm{Cr} & \mathrm{Mn} & \mathrm{Zr} \\ \text { in \% } & 0.03 & 0.03 & 8.12 & 2.00 & 2.00 & <0.01 & <0.01 & 0.12\end{array}$

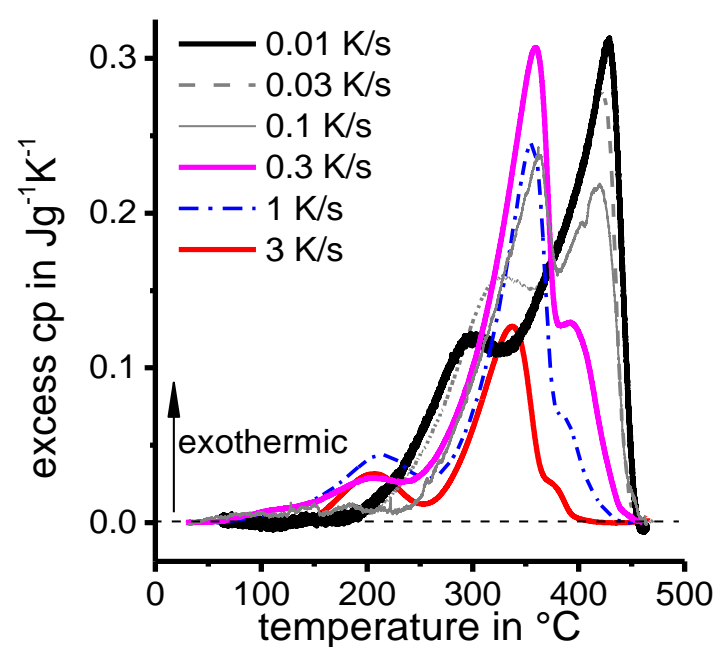

Fig. 1: Selected DSC cooling curves of A) AA7055, B) AA7085 and C) AA7085 lowCu showing cooling after solution annealing with different rates.
B) cooling AA7085 from $480{ }^{\circ} \mathrm{C} 1 \mathrm{~h}$

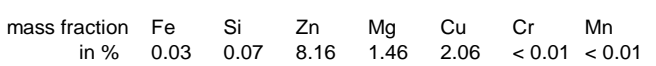



C) cooling AA7085 ${ }_{\text {low } \mathrm{Cu}}$ from $480^{\circ} \mathrm{C} 1 \mathrm{~h}$ $\begin{array}{cllllllll}\text { mass fraction } & \mathrm{Fe} & \mathrm{Si} & \mathrm{Zn} & \mathrm{Mg} & \mathrm{Cu} & \mathrm{Cr} & \mathrm{Mn} & \mathrm{Zr} \\ \text { in \% } & 0.02 & 0.12 & 7.82 & 1.37 & 0.91 & <0.01 & <0.01 & 0.12\end{array}$




Fig. 1 displays selected cDSC curves of AA7085, AA7085lowCu and AA7055; cDSC for AA7020C, AA7150C and AA7049A are presented elsewhere [11,18]. Depending on cooling rate these cDSC curves show up to 3 main reactions: a high temperature reaction (HTR, typically $450{ }^{\circ} \mathrm{C}$ down to $\sim 350{ }^{\circ} \mathrm{C}$ ), a medium temperature reaction (MTR, $\sim 350^{\circ} \mathrm{C}$ down to $250^{\circ} \mathrm{C}$ ) and a lower temperature reaction (LTR, $\sim 250^{\circ} \mathrm{C}$ down to $\sim 150^{\circ} \mathrm{C}$ ). These reactions partially overlap, with the degree of overlap depending on alloy composition and cooling rate.

To supplement microstructure data available in the literature we performed TEM and SEM on alloy I cooling rate combinations that have hitherto not been reported on, in combination with interrupted quench experiments. The latter experiments, illustrated in Fig. 2, allowed us to identify the phases formed in the reactions seen in the cDSC curves. To determine which phase precipitates in each reaction, we cooled samples at rates for which the reaction of interest is dominating and clearly detectable (Fig. $2 \mathrm{~A}$ )

A)
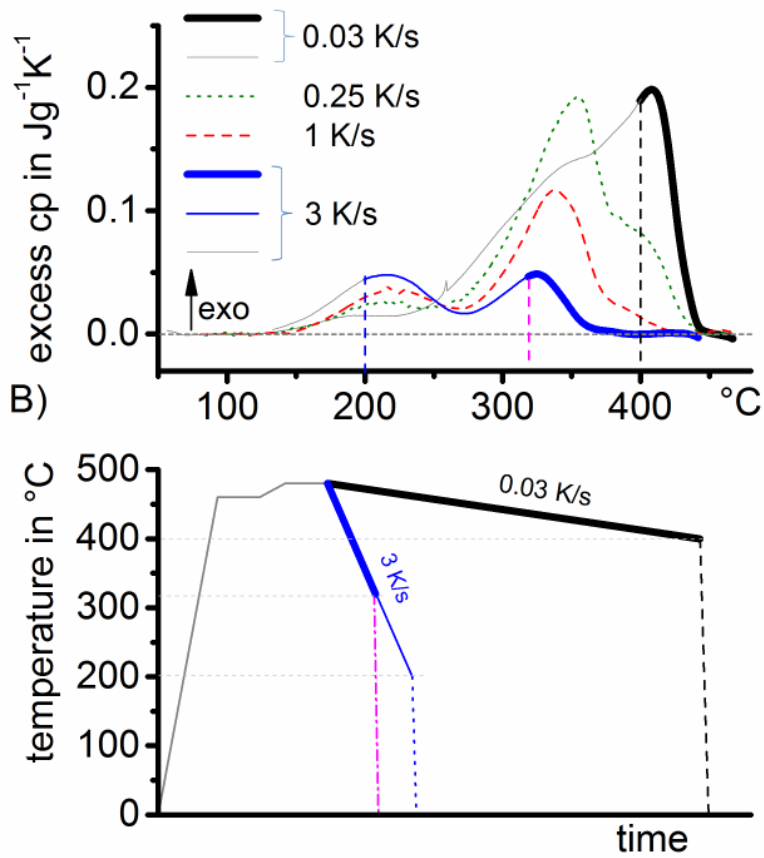

Fig. 2: Scheme of step-quench experiments. A) Selected DSC curves of relevant cooling rates of AA7150c. Exemplary cooling rates and temperatures at which the precipitation state was frozen (by overcritical quenching) are highlighted. B) Schematic temperature-time profile of the step quench experiments. down to a temperature just below the temperature corresponding to the maximum heat flow with overcritical fast quenching rate (Fig. $2 \mathrm{~B}$ ). The cooling rate and temperature were chosen individually for each alloy. For cooling rates in which one reaction clearly dominates additional samples were investigated after cooling with a constant rate to room temperature.

To identify the reaction(s) involved in the HTR we performed TEM and SEM work. Fig. 3 shows the SEM images of an AA7150 sample cooled at $0.03 \mathrm{~K} / \mathrm{s}$ to RT. TEM-SAED and EDS revealed that the large particles with irregular shapes and dimensions up to several tens of micrometres are 
$\mathrm{S}-\mathrm{Al}_{2} \mathrm{CuMg}$ precipitates. Step quench experiments confirmed that S- $\mathrm{Al}_{2} \mathrm{CuMgprecipitates} \mathrm{form} \mathrm{during}$ the HTR. In SEM studies, the $\mathrm{S}-\mathrm{Al}_{2} \mathrm{CuMg}$ phase is also seen to have nucleated on $\mathrm{Al}_{7} \mathrm{Cu}_{2} \mathrm{Fe}$ intermetallic phases (see Fig. 3). Thus the present TEM and SEM work shows the formation of S$\mathrm{Al}_{2} \mathrm{CuMg}$ phase is responsible for the HTR in the $\mathrm{Cu}$ containing alloy $\mathrm{AA} 7150 \mathrm{C}$ and previous work has shown that S-Al 2 CuMgphase formation also occurs in this high temperature range for a range of other Cu containing $7 x x x$ alloys $[19,20]$.

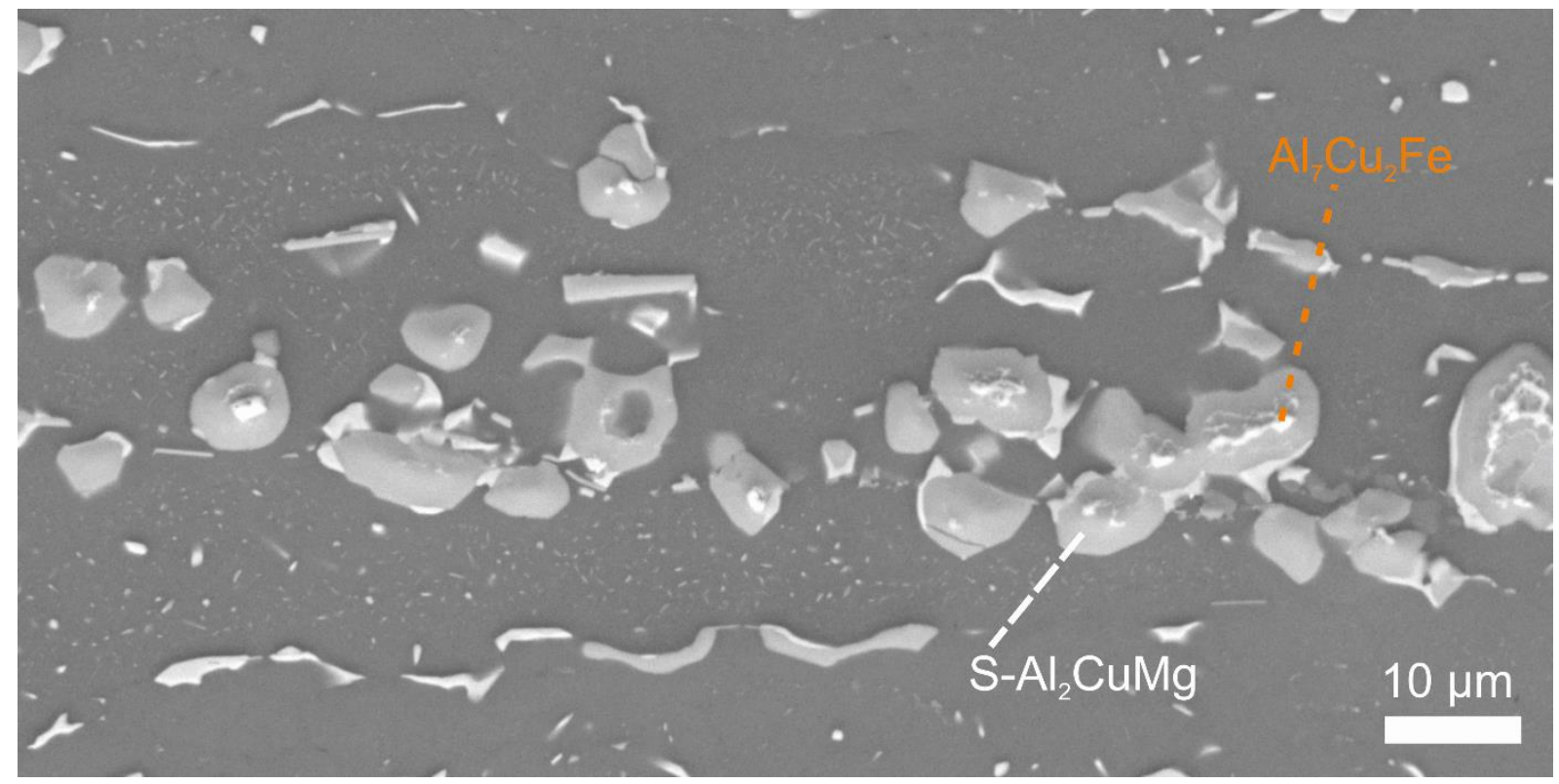

Fig. 3: SEM BEl image of an AA7150 sample cooled with $0.03 \mathrm{~K} / \mathrm{s}$ to RT. Very coarse S-Al2 CuMg particles are visible (undefined shapes, dimensions up to some tens of $\mu \mathrm{m})$. The $\mathrm{S}-\mathrm{Al}_{2} \mathrm{CuMg}$ precipitates appear to have nucleated at $\mathrm{Al}_{7} \mathrm{Cu}_{2} \mathrm{Fe}$ particles. Besides these two precipitation species, additional much finer $\eta-\mathrm{Mg}(\mathrm{Zn}, \mathrm{Al}, \mathrm{Cu})_{2}$ precipitates are visible.

AA7020 contains no $\mathrm{Cu}$ and hence no S-Al2CuMg phase forms in these samples. In this alloy, which contains about 0.1 at $\% \mathrm{Si}$, some limited formation of $\mathrm{Mg}_{2} \mathrm{Si}$ is detected at very slow cooling rates - see Fig. 4. At $0.005 \mathrm{~K} / \mathrm{s}$ about $0.3 \mathrm{vol} \% \beta-\mathrm{Mg}_{2} \mathrm{Si}$ is observed, which corresponds well with expected amounts at the completion of the reaction [8]. The temperature range and cooling rate range of the HTR in the AA7020 alloy correspond well with the model for Al-Mg-Si alloys developed recently [8]. Thus in alloys which contain $\mathrm{Cu}, \mathrm{Mg}$ and $\mathrm{Si}$ two phases may contribute to the HTR: S-Al2CuMgand $\beta-\mathrm{Mg} 2 \mathrm{Si}$ 
Fig. 5 shows two images from step-quench experiments on AA7150. The image in Fig. 5A) was recorded on a sample cooled at $3 \mathrm{~K} / \mathrm{s}$ to $320^{\circ} \mathrm{C}$. According to the CDSC results (Fig. 2) in this state only precipitates of the MTR should be present as the HTR is suppressed at this high cooling rate. TEM SAED and EDS analysis revealed $\eta-\mathrm{Mg}(\mathrm{Zn}, \mathrm{Al}, \mathrm{Cu})_{2}$ precipitates nucleated on $\mathrm{Al}_{3} \mathrm{Zr}$ dispersoids and this finding is in line with published TEM and SEM work on several Al-Zn-Mg-Cu alloys [2,11,16,21-23].

The sample of Fig. $5 \mathrm{~B}$ ) was cooled at $3 \mathrm{~K} / \mathrm{s}$ to $200^{\circ} \mathrm{C}$. cDSC data (Fig. $2 \mathrm{~A}$ ) shows that in this state also precipitates belonging to the LTR should be present, and Fig. $5 \mathrm{~B}$ ) reveals that besides dot-like $\mathrm{Al}_{3} \mathrm{Zr}$ dispersoids another phase in the form of thin plates is present.

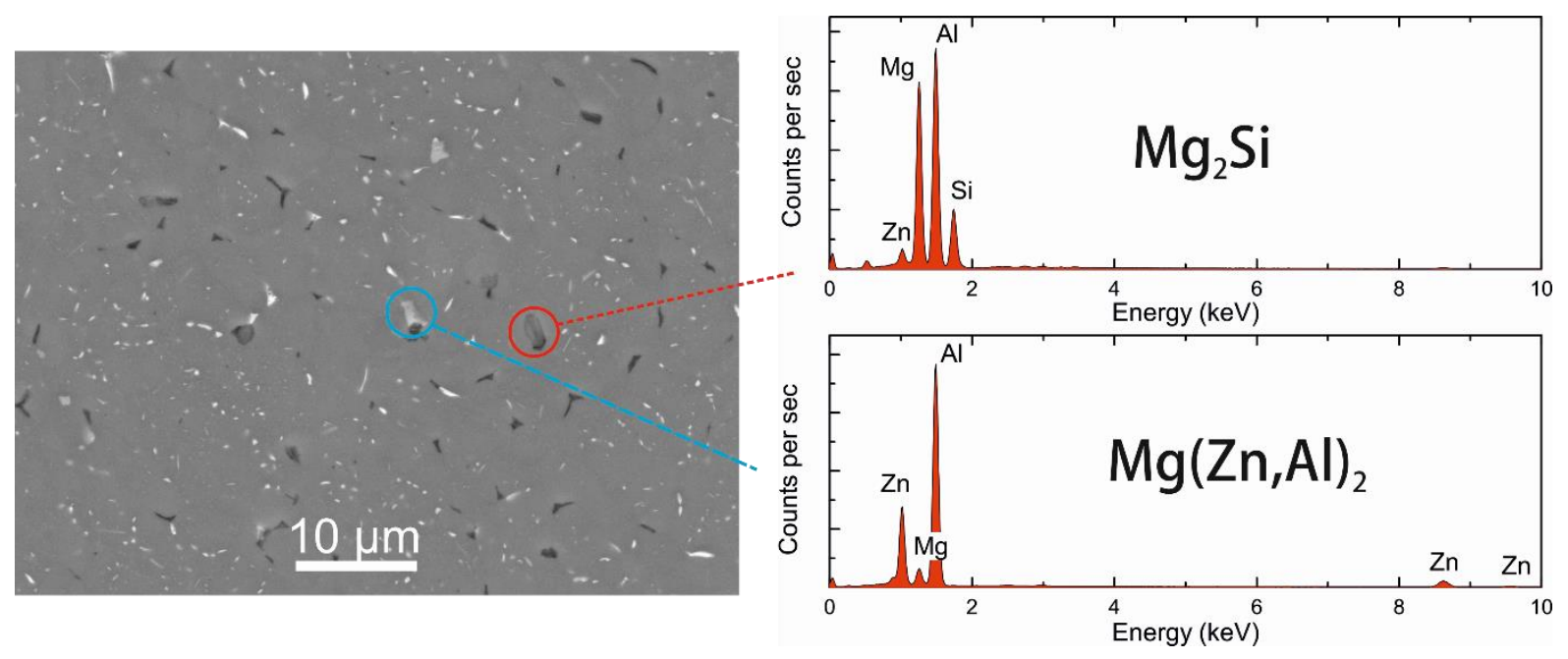

Fig. 4: Backscattered SEM image of alloy AA7020 sample cooled at $0.005 \mathrm{~K} / \mathrm{s}$ and corresponding EDS analysis results for large particles with different image contrast showing that they correspond to $\eta$-phase $\left(\mathrm{Mg}(\mathrm{Zn}, \mathrm{Al})_{2}\right)$ and $\beta$-phase $\left(\mathrm{Mg}_{2} \mathrm{Si}\right)$. 


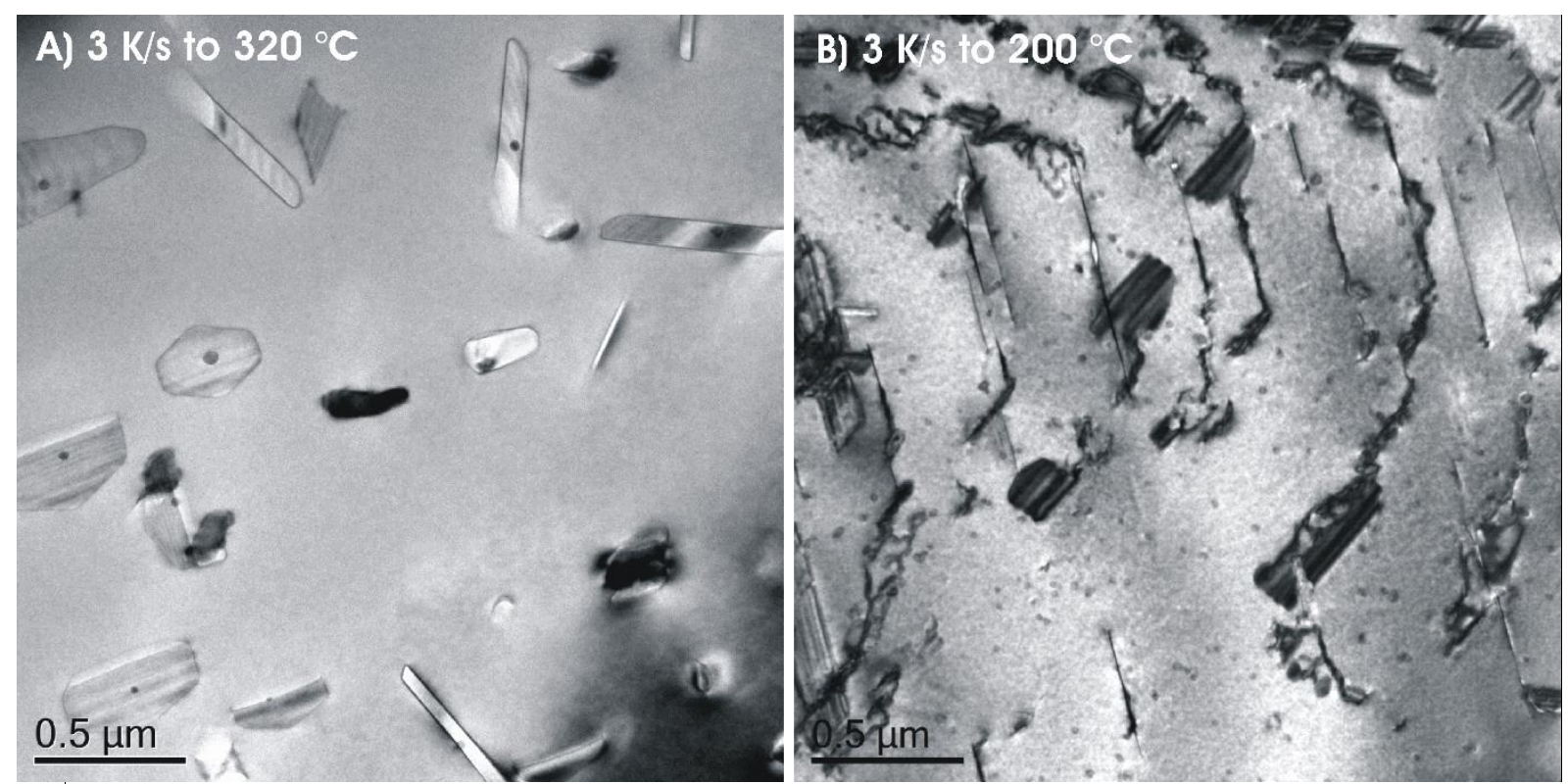

Fig. 5: TEM images (bright field) of AA7150 step quenched at a cooling rate of $3 \mathrm{~K} / \mathrm{s}$ in A) to $320{ }^{\circ} \mathrm{C}$ and in $\mathrm{B}$ ) to $200{ }^{\circ} \mathrm{C}$. In $\mathrm{A}$ ) two types of precipitates can be seen in a recrystallized grain. The irregular shaped precipitates with dimensions of typically $50-500 \mathrm{~nm}$ are $\eta-\mathrm{Mg}(\mathrm{Zn}, \mathrm{Al}, \mathrm{Cu})_{2}$ and appear to have all nucleated on a spherical $\mathrm{Al}_{3} \mathrm{Zr}$ particle (typical diameter 20-50 nm). In B) which was cooled further down to $200^{\circ} \mathrm{C}$, additionally thin plate like precipitates corresponding to the LTR can be found. $\mathrm{Al}_{3} \mathrm{Zr}$ dispersoids are also present appearing as small dots.

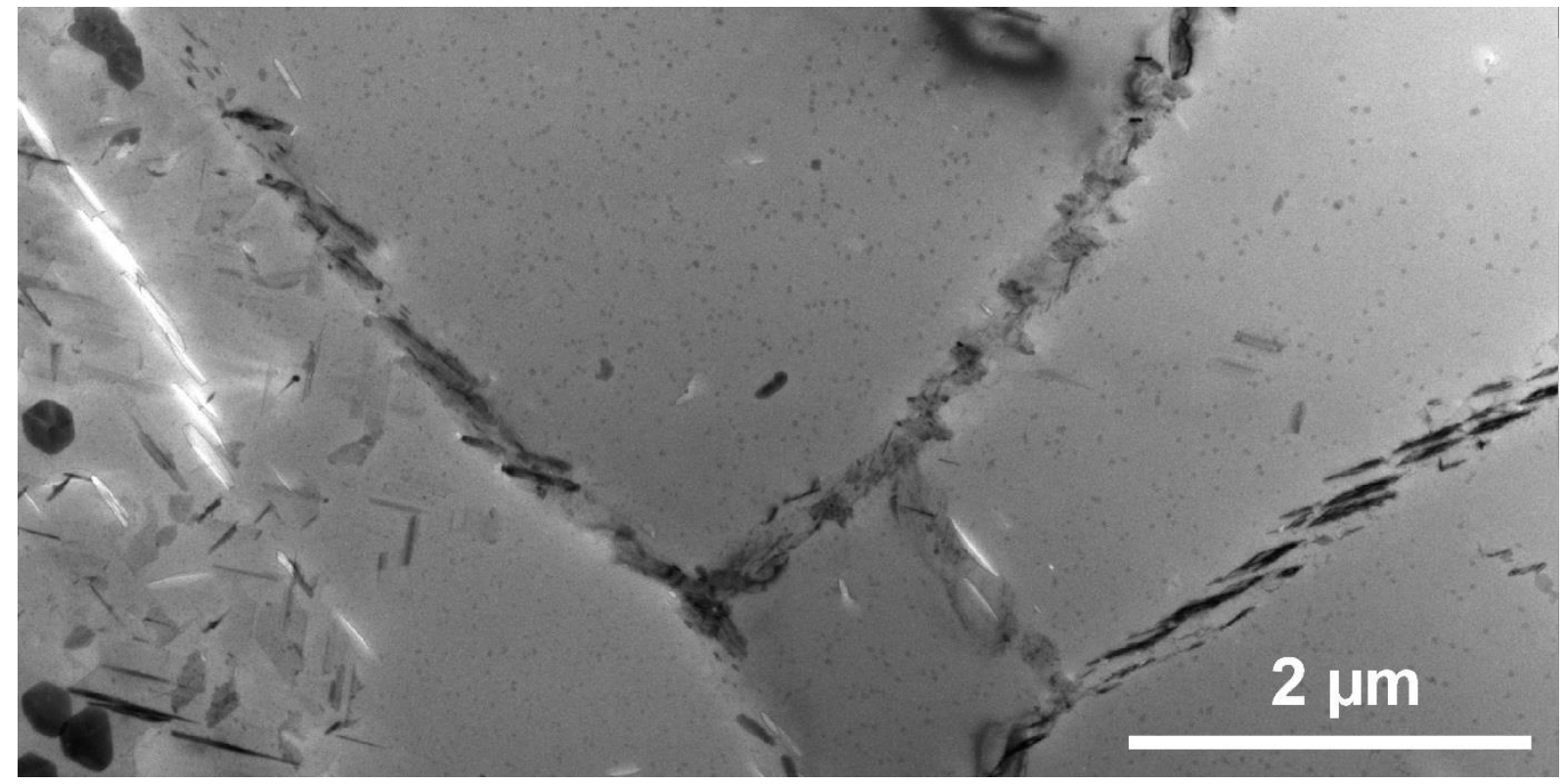

Fig. 6: TEM image of an air-cooled AA7150 sample (average cooling rate $1 \mathrm{~K} / \mathrm{s}$ ) showing a recrystallized grain on the left side and some subgrains on the right. It can be seen, that the quenched-induced $\eta-\mathrm{Mg}(\mathrm{Zn}, \mathrm{Al}, \mathrm{Cu})_{2}$ precipitates preferentially nucleate at grain/subgrain boundaries and also appear inside the recystallised grain nucleating at $\mathrm{Al}_{3} \mathrm{Zr}$ dispersoids. 
At a medium cooling rate (air cool, average cooling rate $1 \mathrm{~K} / \mathrm{s}$ ) the MTR dominates and the quenchinduced phases in the AA7150 alloy precipitate preferentially within the recrystallised grains (as illustrated in Fig. 6). During cooling/quenching the $\eta-\mathrm{Mg}(\mathrm{Zn}, \mathrm{Al}, \mathrm{Cu})_{2}$ precipitates nucleate preferentially on defects such as dislocations, grain boundaries and free surfaces that can reduce the activation energy barrier including dispersoids-matrix interfaces that are incoherent $[3,23]$. Fig. 6 shows the microstructure of an air-cooled sample (average cooling rate $1 \mathrm{~K} / \mathrm{s}$ ). DSC (Fig. $2 \mathrm{~A}$ ) reveals that during this type of cooling the vast majority of the precipitates will form by the MTR and Fig. 6 reveals a large number of quench-induced $\eta-\mathrm{Mg}(\mathrm{Zn}, \mathrm{Al}, \mathrm{Cu})_{2}$ precipitates nucleated on $\mathrm{Al}_{3} \mathrm{Zr}$ dispersoids in a recrystallised grain and on grain boundaries. In unrecrystallised subgrains like on the right part of Fig. 6 no quench induced $\eta-\mathrm{Mg}(\mathrm{Zn}, \mathrm{Al}, \mathrm{Cu})_{2}$ precipitates can be found, as the dispersoids here are coherent with the matrix. In line with TEM analysis of a AA7055 alloy [24], no or very few $\eta-\mathrm{Mg}(\mathrm{Zn}, \mathrm{Al}, \mathrm{Cu})_{2}$ precipitates are seen to nucleate on the coarser intermetallics in our alloys at cooling rates faster than $1 \mathrm{~K} / \mathrm{s}$. This is due to the fact that most of the surface area available for nucleation is provided by the dispersoids and grain and sub-grain boundaries (see Section 5). These $\eta-M g(Z n, A l, C u)_{2}$ precipitates on grain boundaries are ubiquitous in 7xxx alloys and are present even in samples cooled at relatively high rates (about $100 \mathrm{~K} / \mathrm{s}$, [2]) in Al-Zn-Mg alloys with Zn contents lower than the present alloys [2].

Fig. 7 shows an overview of precipitates nucleated in the grain and on the grain boundary for the alloys AA7085, AA7085lowCu, AA7055, AA7150c and AA7020 using SEM in BEl mode. For these samples, the cooling rates employed are such that $\sim 50 \%$ of the maximum $\Delta H$ of the MTR has been achieved. The left part of the figure shows a lower magnification, whilst the right part shows more details in a higher magnification. $\mathrm{S}-\mathrm{Al}_{2} \mathrm{CuMg}$ phase formation is suppressed (nearly) completely at the cooling rates employed for the samples in Fig. 7 and the bright precipitates visible in Fig. 7 are $\eta-M g(Z n, A l, C u)_{2}$ precipitates. The images show that in the MTR for AA7020 nearly all of the $\eta-\mathrm{Mg}(\mathrm{Zn}, \mathrm{Al}, \mathrm{Cu})_{2}$ form on grain boundaries, whilst for the MTR in the other alloys the precipitation in the grains is dominant, with precipitation on grain boundaries occurring as well. 
The platelet phase formed in the LTR has been studied in detail using HRTEM. Fig. 8A) shows a TEM bright field image of platelet phase precipitates in AA7150 after cooling at $10 \mathrm{~K} / \mathrm{s}$ to room temperature. Fig. $8 \mathrm{~B}$ ) shows an HAADF-STEM image of one of such plates and it appears that the phase is attached to a nanometer sized void. This is suggesting it either nucleated on a void or that the solute atoms forming the precipitate were linked to vacancies which condensed to a nanovoid. Next to the platelet phase some few dispersoids free of any other precipitates can be seen, showing that the platelet phase does not form on $\mathrm{Al}_{3} \mathrm{Zr}$ dispersoids. Fig. ${ }_{8} \mathrm{C}$ ) shows an EDS mapping of a single platelet phase revealing the segregation of predominantly $\mathrm{Zn}$ and $\mathrm{Cu}$. The EDS results indicate a $\mathrm{Zn} / \mathrm{Cu}$ ratio of about 3/2.

A range of further TEM, SEM and EDS experiments were reported elsewhere [25] and all data is consistent with the above interpretations of HTR and MTR reactions. Thus, in summary, the present results in combination with literature data show that during the quench 4 main reactions occur: formation of S-Al2CuMg phase (HTR1), formation of $\mathrm{Mg}_{2} \mathrm{Si}(\mathrm{HTR} 2)$, formation of $\eta-\mathrm{Mg}(\mathrm{Zn}, \mathrm{Cu}, \mathrm{Al})_{2}$ phase (MTR) and formation of $\mathrm{Zn}-\mathrm{Cu}$ plates (LTR). The S-Al2CuMg phase forms predominantly on $\mathrm{Cu}$ containing coarse particles ( $\mathrm{S}-\mathrm{Al}_{2} \mathrm{CuMg}$ and $\left.\mathrm{Al}_{7} \mathrm{Cu}_{2} \mathrm{Fe}\right)$ and on grain boundaries. The formation of $\eta-\mathrm{Mg}(\mathrm{Zn}, \mathrm{Cu}, \mathrm{Al})_{2}$ occurs in two distinct types of location: on dispersoids and on grain/subgrain boundaries, and the platelet LTR particles form in the grains apparently associated with vacancy clusters.

Our DSC experiments further show a further minor reaction in the temperature range below the LTR down to about $50{ }^{\circ} \mathrm{C}$, which we will term very low temperature reaction (VLTR). However, due to cooling control and signal to noise limitations of the DSC devices this small reaction in this temperature range can not be consistently assessed by cDSC. Nevertheless, for AA7085 and AA7085 lowCu the vLTR reaction is clearly detected at rates of 0.3 and $1 \mathrm{~K} / \mathrm{s}$ in Fig. 1, which are about optimal cooling rates for the DSC used for this rates and cooling was in control (at constant rate) down to about $30^{\circ} \mathrm{C}$. 

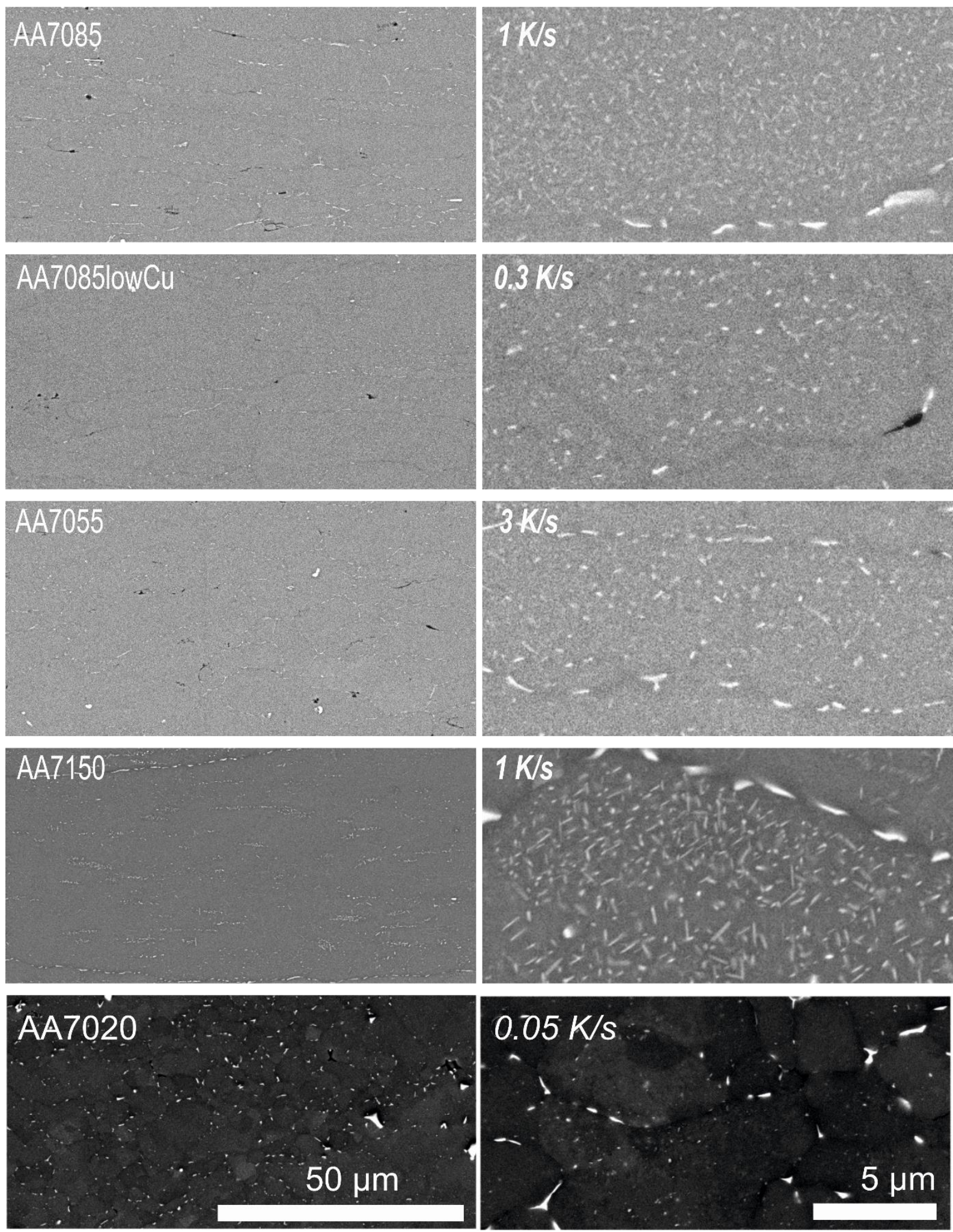

Fig. 7: SEM backscattered mode images for samples of AA7085, AA7085lowCu, AA7055, AA7150 and AA7020 cooled at the respective rates at which $\sim 50 \%$ of the maximum $\Delta H$ of the MTR has been achieved. Left part low magnification, right part higher magnification. For all alloys nearly all quenched in precipitates visible here are $\eta-\mathrm{Mg}(\mathrm{Zn}, \mathrm{Al}, \mathrm{Cu})_{2}$ precipitates. 

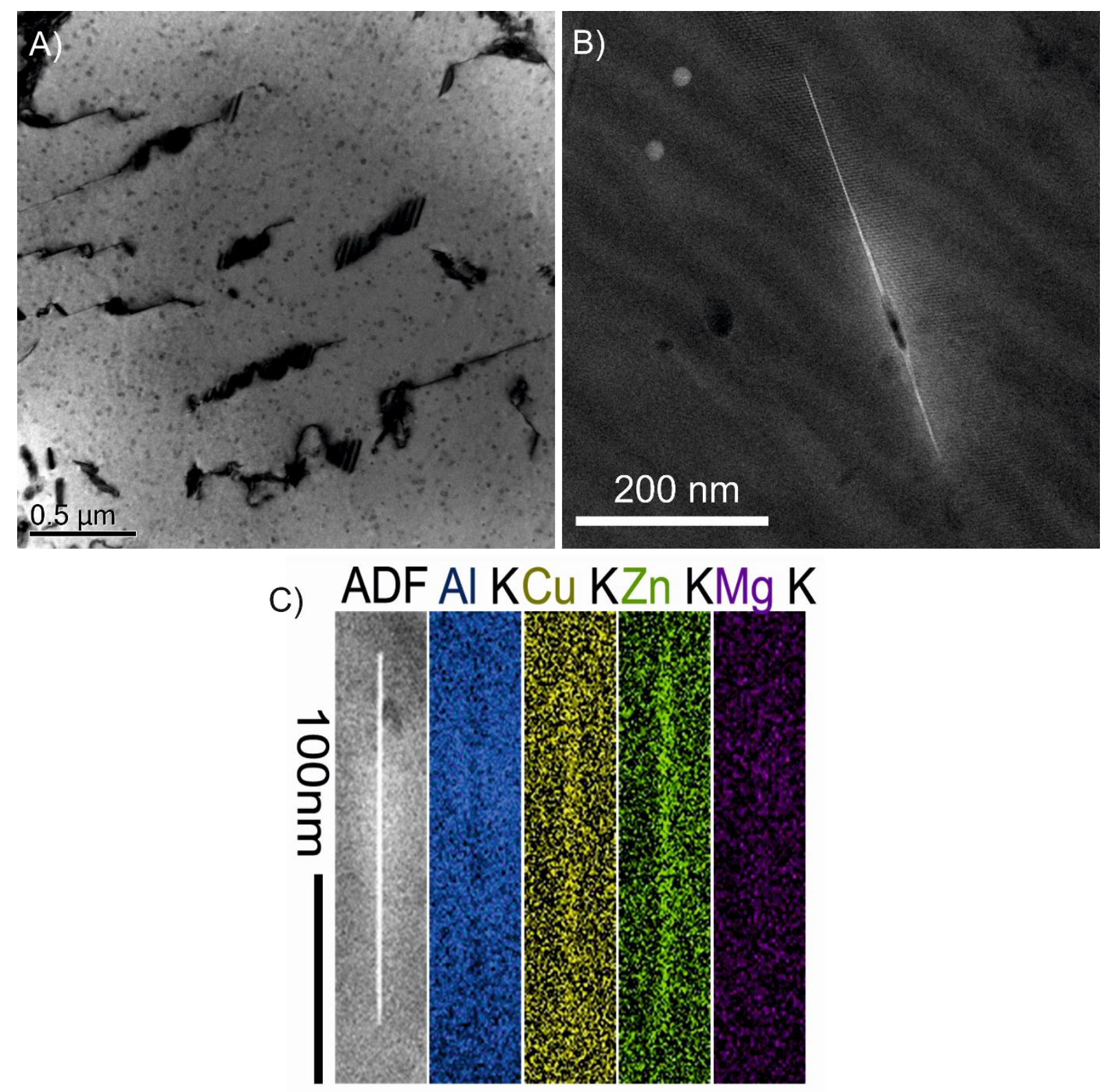

Fig. 8: HAADF-STEM figures of AA7150C A) showing several platelet structures ( 200-400 nm length) together with several $\mathrm{Al}_{3} \mathrm{Zr}$ dispersoids after cooling at $10 \mathrm{~K} / \mathrm{s}$ to room temperature. B) showing the platelet structure after cooling at $3 \mathrm{~K} / \mathrm{s}$ to $200{ }^{\circ} \mathrm{C}$. The thin plate precipitate is attached to a void. C) EDS mapping (together with an ADF image left) of a single platelet phase, showing the platelet phase consists predominantly of $\mathrm{Zn}$ and some $\mathrm{Cu}$.

We conclude that according to our HRTEM results the LTR in the temperature range of about 250$150{ }^{\circ} \mathrm{C}$ is dominated by the precipitation of a $\mathrm{Zn}$-Cu rich thin plate phase. At even lower temperatures of about 150 to $50^{\circ} \mathrm{C}$ additionally co-clusters may precipitate. This explains the detection of a Guinier radius decrease in SAXS experiments on continuous cooling of AA7449 below $100{ }^{\circ} \mathrm{C}$ in $[26,27]$. The $\mathrm{Zn}-\mathrm{Cu}$ rich thin plate phase as well as clusters contribute to strength and during artificial ageing the clusters are thought to further evolve into fine $\eta^{\prime}$ hardening precipitates. 


\section{A model for precipitation during quenching and subsequent age hardening}

\subsection{A model for quench induced precipitation}

\section{At the start of the quench}

As a starting point of the model, first the amounts of undissolved phases (coarse intermetallics and dispersoids) present at the start of the quench are predicted. The main undissolved phases present in Cu-containing 7xxx alloys are $\mathrm{Al}_{6}(\mathrm{Mn}, \mathrm{Fe})$ and $\mathrm{Al}_{7} \mathrm{Cu}_{2} \mathrm{Fe}[28,29]$, and if the $\mathrm{Cu}$ and $\mathrm{Mg}$ content is high, some undissolved $\mathrm{S}-\mathrm{Al}_{2} \mathrm{CuMg}$ phase particles will be present $[30,31]$. If $\mathrm{Cr}$ is present a $\mathrm{Cr}$ containing phase will form which in many alloys will be $\mathrm{Al}_{18} \mathrm{Mg}_{3} \mathrm{Cr}_{2}$ [32,33]. Details of the predictions for the amounts of these phases are provided in the Appendix. This part of the model provides the concentrations of elements in the Al-rich matrix phase after solution treatment (i.e. just prior to start of the quench), which are denoted as $X_{\mathrm{Mg}, \mathrm{st}}, \mathrm{XZn}_{\mathrm{Zn}, \mathrm{st}}$, etc.

General structure of the model for quench induced precipitation: extended volume and reaction rates

\section{in the extended volume}

The present model expands the modelling strategy outlined in [8]. One simplification adopted in that model, again adopted here to drastically improve the model efficiency through reducing computational complexity, is the use of consecutive reactions, e.g. the interaction between the reactions occurs through taking the Al-rich phase composition achieved after one reaction to be the starting state of the next reaction. Following the findings in Section 3 we consider 4 consecutive reactions in the model: formation of S-Al ${ }_{2} \mathrm{CuMg}$ phase (HTR1), formation of $\mathrm{Mg}_{2} \mathrm{Si}$ (HTR2), formation of $\eta-\mathrm{Mg}(\mathrm{Zn}, \mathrm{Cu}, \mathrm{Al})_{2}$ phase (MTR) and formation of Zn-Cu-rich thin plates (LTR).

A key element in the model is the use of the extended volume concept [6,34-38], the conceptual volume in which particles grow without being limited by the interaction with diffusion fields from other particles. This approach has been shown to be computationally very efficient and provide predictions for diffusion field impingement that outperform other models [5,6]. Hence we formulate the formation of precipitates in terms of the extended fraction transformed, $\alpha_{\text {ext }}$, i.e. the fraction transformed that would 
form in the extended volume. As provided before [39], the extended volume fraction, $\alpha_{\text {ext, }}$ can be represented as

$$
\alpha_{\text {ext }}=(k Q)^{n}
$$

where $Q$ is the quench factor [39], $k$ is a rate constant and $n$ is the reaction exponent $[5,38]$. Following [39], $Q$ is defined as:

$$
Q=\int_{t=0}^{t} \frac{d t}{C_{t}}
$$

For constant cooling rates, $Q$ is proportional to the time during the quench, which in turn is proportional to the inverse of the cooling rate. Thus we find the basic expression for the extended volume fraction during cooling at constant rate:

$$
\alpha_{\text {ext }}=(k / \beta)^{n}
$$

where $\beta$ is the cooling rate. The temperature at which the reaction occurs depends on alloy composition and the solvus of the precipitating phase. In [8] we derived that the ratio of diffusion rate, $D(T)$, where $T$ is the temperature, and diffusion pre-exponential constant, $D$ o, is given by [8]:

$$
\frac{D}{D_{o}}=\left(\frac{\prod_{i} c_{i}^{a_{i}}}{C}\right)^{\frac{E_{D}}{\Delta H}}
$$

where $c_{\mathrm{i}}$ is the concentration of alloying element $\mathrm{i}$ in solution, $\mathrm{C}$ is a constant, $\Delta H$ is the enthalpy of formation of the phase and $E_{\mathrm{D}}$ is the activation energy for the rate-determining process of the reaction (typically the diffusion of the slowest diffusing element). The latter equation was verified through comparison of extensive cDSC data on a range of alloys with model predictions [8]. The functional relation between the formation rate of the phase, $k_{2}$, and the composition for the case that the number of growing precipitates is independent of the solute content of the alloy (this is the case for a limited number of nuclei), is given by:

$$
k_{2}=k_{o} \frac{D}{D_{o}}\left[y_{Q I P}(\max )\right]^{p}
$$


where $y_{Q I P}(\max )$ is the maximum amount of precipitates that can form, and $p$ equals $1 / 3$ [8]. The constant $k_{0}$ needs to be fitted for each reaction, whilst all the other constants in the model can, in principle, be obtained from investigation of mechanisms and thermodynamics involved. These basic elements of the model will be further expanded below, but first we will define the reactions that are to be considered in the model.

\section{The reactions during the quench}

The $\mathrm{S}-\mathrm{Al}_{2} \mathrm{CuMg}$ and $\beta\left(\mathrm{Mg}_{2} \mathrm{Si}\right)$ phases formed in the HTR reactions are treated as stoichiometric compounds, the fixed compositions are taken as $\mathrm{Al}_{2} \mathrm{CuMg}$ and $\mathrm{Mg}_{2} \mathrm{Si}$. The solvus and enthalpy of formation of $\mathrm{Al}_{2} \mathrm{CuMg}$ is based on Refs. $[30,40]$. The solvus, enthalpy, activation energy and all other kinetic parameters of formation of $\beta\left(\mathrm{Mg}_{2} \mathrm{Si}\right)$ are taken as described in [8].

The MTR is due to $\eta-\mathrm{Mg}(\mathrm{Zn}, \mathrm{Cu}, \mathrm{Al})_{2}$ phase forming on grain and subgrain boundaries [19] and dispersoids (e.g. $[3,23,41-45])$; and this reaction to a large extent determines the resulting mechanical properties of the material in quench conditions that are of industrial relevance. Hence we will pay special attention to this reaction. The $\eta-\mathrm{Mg}(\mathrm{Zn}, \mathrm{Cu}, \mathrm{Al})_{2}$ phase is based on the $\mathrm{MgZn} 2$ topologically close-packed Laves phase and the $\mathrm{Cu}$ and $\mathrm{Al}$ contents have been discussed in several studies $[7,46]$. The enthalpy (and hence the stability) of topologically close-packed Laves phases such as $M g Z n_{2}$ is highly dependent on the atomic size $[47,48]$ and the electronic structure $[49,50]$. Cu has a valence electronic configuration that is identical to that of $\mathrm{Zn}(3 \mathrm{~d} 10)$ whilst it has a much smaller atomic radius than $\mathrm{Mg}$, and thus $\mathrm{Cu}$ is likely to replace $\mathrm{Zn}$ in the $\eta$ structure. First principles modelling indicates that the enthalpy of formation of the $\eta$ phase increases substantially when $\mathrm{Al}$ and $\mathrm{Cu}$ replace $\mathrm{Zn}$ atoms in a 12 atom unit cell, and particularly the composition change from $\mathrm{MgZn}_{2}$ to $\mathrm{Al}_{1} \mathrm{Zn}_{5} \mathrm{Cu}_{2} \mathrm{Mg}_{4}$ provides a much more stable composition with an enthalpy that is increased by $35 \%$ [7]. However, as the diffusion rate of $\mathrm{Cu}$ is an order of magnitude lower than that of $\mathrm{Mg}$ and $\mathrm{Zn}$ this composition will not be achieved when the $\eta$ phase forms during the cooling. To address this, the present model considers that during nucleation and growth of the $\eta-\mathrm{Mg}(\mathrm{Zn}, \mathrm{Cu}, \mathrm{Al})_{2}$ phase the $\mathrm{Cu}$ atoms are effectively stationary in the Al-rich phase and 
hence the average $\mathrm{Cu}$ content of the $\eta-\mathrm{Mg}(\mathrm{Zn}, \mathrm{Cu}, \mathrm{Al})_{2}$ phase particles will equal the $\mathrm{Cu}$ content of the alloy. Thus in the model the $\eta-\mathrm{Mg}(\mathrm{Zn}, \mathrm{Cu}, \mathrm{Al})_{2}$ phase precipitates nucleated during the cooling are effectively made up of units of $\mathrm{Mg}_{4} \mathrm{Zn}_{8}$ and $\mathrm{Al}_{1} \mathrm{Zn}_{5} \mathrm{Cu}_{2} \mathrm{Mg}_{4}$.

The incorporation of $\mathrm{Cu}$ and $\mathrm{Al}$ in $\eta$ will enhance its rate of formation through several factors:

i. the increase in enthalpy change $\Delta H$ increases the solvus temperature of the phase and hence the precipitation rate is higher (due to the increased diffusivity);

ii. the entropy $S$ is increased which increases the solvus temperature of the phase;

iii. the maximum amount of phase that can form is increased;

iv. an enhanced number of growing nuclei;

v. less $\mathrm{Zn}$ needs to diffuse to form the phase.

Factors i and iii are incorporated in the model through changing the enthalpy change $\Delta H$, entropy $S$ and $y$, which become dependent on the $\mathrm{Cu}$ content, using the theory in [8]. The entropy $S$ is incorporated by replacing the simplified expression of free energy $\Delta G$ as $\Delta H$ by its full form $(\Delta G=\Delta H$ TS), i.e.:

$$
\frac{D}{D_{o}}=\left(\frac{\prod_{i} c_{i}^{a_{i}}}{C}\right)^{\frac{E_{D}}{\Delta G-T S}}
$$

Homogeneous and heterogeneous nucleation depends on a range of factors, including interfacial energy, the diffusion rate and the critical particle size. Of these factors, the $\mathrm{Cu}$ and $\mathrm{Al}$ content have a strong influence on nucleation particularly through their indirect influence on the diffusion rate (via the increased solvus).

There is no data available on the interfacial energies between the $\eta$ phase and matrix, or on the influence of $\mathrm{Cu}$ (and $\mathrm{Al}$ ) incorporation on these interfacial energies. As there is no indication that the latter is a particularly strong effect, we will not consider this in the model. The mass density of $\mathrm{MgZn}_{2}$ is $5.09 \mathrm{~g} / \mathrm{cm}^{3}$ [51], which is equivalent to an atomic density that is virtually identical to that of the matrix, 
and thus volume misfit strains on precipitation will be minimal. (For the metastable $\eta^{\prime}$ phase the incorporation of $\mathrm{Cu}$ atoms is also considered to enhance phase stability $[43,52,53]$.

The initial rate of formation of $\eta$ phase nuclei will be proportional to the amount of sites available, which is determined by the grain/subgrain boundary area and the particle-matrix interface area for the undissolved particles present at the start of the quench. Both are incorporated in the model. The amount of grain boundaries available is calculated on the basis on the grain and subgrain sizes reported in the literature and Section 3, and the recrystallized fractions of the alloys. The number density and total particle-matrix interface area of particles present at the start of the quench is obtained as outlined in the Appendix. We take $\mathrm{r}_{\mathrm{Al} 18 \mathrm{Mg} 3 \mathrm{Cr} 2}=30 \mathrm{~nm}[23,54], \mathrm{r}_{\mathrm{Al} 7 \mathrm{Cu} 2 \mathrm{Fe}}=2000 \mathrm{~nm}[55], \mathrm{r}_{\mathrm{S}}=1000 \mathrm{~nm}$ [55]). Recent work on Mn containing alloys shows $\mathrm{Al}_{6}(\mathrm{Mn}, \mathrm{Fe})$ particles in an alloy with relatively low $\mathrm{Mn}$ content $(0.1 \mathrm{at} \%)$ are thin plates (average thickness about $40 \mathrm{~nm}$ in an alloy heat treated at $520^{\circ} \mathrm{C}$ ) [56]. These particles form thin plates due to very good coincidence site matching between lattice points in $\left(\begin{array}{lll}0 & 0 & 1\end{array}\right)_{p}$ and $\left(\begin{array}{lll}3 & -1 & 5\end{array}\right)_{m}$ planes in selected orientation relations [56]. The average thickness of the $\mathrm{Al}_{6}(\mathrm{Mn}, \mathrm{Fe})$ for the present alloys is obtained using the latter data by Li et al. [56] and coarsening data in Kong et al. [57] (showing the activation energy for coarsening to be $200 \mathrm{~kJ} / \mathrm{mol}$ ) as $20 \mathrm{~nm}$. $\mathrm{Al}_{3} \mathrm{Zr}$ particles in unrecrystallised grains are coherent with the matrix and precipitates generally do not nucleate on them (e. g. [3,23]). In the recrystallized grains, which are substantially larger than subgrains, the $\mathrm{Al}_{3} \mathrm{Zr}$ particles are incoherent and $\eta$ phase does nucleate on those particles $[3,23,58]$. The radius of the $\mathrm{Al}_{3} \mathrm{Zr}$ particles is typically 20 $50 \mathrm{~nm}$ [43]. It is known that the presence of $\mathrm{Al}_{18} \mathrm{Mg}_{3} \mathrm{Cr}_{2}$ causes enhanced formation of $\eta-\mathrm{Mg}(\mathrm{Zn}, \mathrm{Cu}, \mathrm{Al})_{2}$ during the quench, and many works have suggested that this is related to the interfacial energy, even though no data on interfacial energy is known. However, it should be noted that the $\mathrm{Al}_{18} \mathrm{Mg}_{3} \mathrm{Cr}_{2}$ phase has a range of stability with variable $\mathrm{Mg}$ content from about $\mathrm{Al}_{17} \mathrm{Cr}_{2} \mathrm{Mg}_{4}$ to $\mathrm{Al}_{19} \mathrm{Cr}_{2} \mathrm{Mg}_{2}$ at $400{ }^{\circ} \mathrm{C}$ [59], whilst it can also dissolve some $\mathrm{Zn}[60,61]$. Hence both $\mathrm{Mg}$ and $\mathrm{Zn}$ are available at the interface to form $\eta-\mathrm{Mg}(\mathrm{Zn}, \mathrm{Cu}, \mathrm{Al})_{2}$, and we can expect that its nucleation and growth rate is substantially higher as compared to formation on the dispersoids that are free of $\mathrm{Mg}$ and $\mathrm{Zn}$. To take account of this we 
propose the following approach. We assume that during nucleation $\eta-\mathrm{Mg}(\mathrm{Zn}, \mathrm{Cu}, \mathrm{Al})_{2}$ forms through consuming $\mathrm{Mg}$ from the surface of the $\mathrm{Al}_{18} \mathrm{Mg}_{3} \mathrm{Cr}_{2}$ involving diffusion of $\mathrm{Mg}$ along the interface. As diffusion along the interface is faster than bulk diffusion and diffusion distances for $\mathrm{Mg}$ are small, it is likely that rather than diffusion of $\mathrm{Mg}$ through the $\mathrm{Al}$ rich matrix phase, diffusion of $\mathrm{Zn}$ becomes the rate limiting diffusional process in the nucleation.

S- $\mathrm{Al}_{2} \mathrm{CuMg}$ phase nucleates on the surface of $\mathrm{Al}_{7} \mathrm{Cu}_{2} \mathrm{Fe}$ and on pre-existing/undissolved $\mathrm{S}$ phase particles, and hence the formation rate is taken as proportional to the surface area of these particles at the start of the quench. As growth starts from these relatively large particles, the reaction will effectively start as 1 dimensional growth and $n$ will be $1 / 2$ for the start of the reaction $[5,62]$. We will adopt this value of $n$ (and not seek to capture the later stages of the reaction, which occurs at extremely slow cooling rates).

Our HRTEM evidenced that during the heat effect associated with the LTR the formation of Zn,Curich thin plate precipitates on $\{111\}$ planes starting at only one atom layer thick for samples is the dominant reaction. Thin plates on $\{111\}$ planes have also been identified in Al-6.0Zn-2.0 Mg-1.0Cu (wt\%) (AA7012) samples aged for short times using HRTEM [63] and in an Al-11.8Zn-1.5 Mg-1.7Cu$0.16 \mathrm{Zr}-0.12 \mathrm{Fe}-0.08 \mathrm{Si}$ alloys aged for $2 \mathrm{~h}$ at RT using HRTEM [64]. Plates on $\{111\}$ planes are also confirmed by first principle calculations to be energetically favourable $[65,66]$. In the present model we will consider these precipitates formed during quenching to contain $\mathrm{Zn}$ and $\mathrm{Cu}$, with $\mathrm{Zn}: \mathrm{Cu}$ ratio as obtained by our EDS work. The very small enthalpy changes caused by the VLTR can not be reliably measured and, therefore, we will not attempt to include them in the enthalpy predictions.

In addition to the 4 phases considered in the model, it is known $[19,20]$ that on very slow cooling $(<0.01 \mathrm{~K} / \mathrm{s})$ also $\mathrm{T}\left(\mathrm{Al}_{2} \mathrm{Mg}_{3} \mathrm{Zn} 3\right)$ phase can form. As these very slow cooling rates have no relevance to the quench sensitivity of these alloys, we will not seek to incorporate this phase in the predictions. We will not make predictions of strength for reactions/microstructures obtained for cases where the $\mathrm{Zn}: \mathrm{Mg}$ ratio in the Al rich matrix phase at any stage during the quench exceeds 8 in the model. Such conditions are thought to result from limitations introduced by approximations made in the model and occur 
generally for alloys with high gross $\mathrm{Zn:Mg}$ ratio $(>1.8)$ at relatively low cooling rates $(<0.1 \mathrm{~K} / \mathrm{s})$. These cooling rates are far removed from relevance to commercial application.

\section{Growth and impingement of diffusion fields in the model}

The diffusion-controlled growth and impingement of diffusion fields is treated with reference to the recently derived [5] model employing the extended volume concept, which was verified through comparison with a wide range of reactions in which the product phases are randomly and homogeneously distributed [5,6]. The model gives the fraction transformed, $\alpha$, as [5]:

$$
\alpha=\frac{\exp \left(-2 \alpha_{e x t}\right)-1}{2 \alpha_{e x t}}+1
$$

The values for the reaction exponent $n$ relate to the mechanisms and or diffusion-controlled reactions $[6,38,67,68]$. We define $n$ based on the general equation for $n[6,38,67,68]$ :

$$
n=N_{\mathrm{dim}} g+B
$$

where $g$ is $\frac{1}{2}$ for diffusion-controlled (parabolic) growth, $B$ is 0 in the case where nucleation ceases very early in the reaction, or 1 for continuous nucleation (at constant nucleation rate in the extended volume), $N_{\text {dim }}$ is the dimensionality of the growth. Thus $n$ is $1 / 2$ for growth for which the rate is determined by onedimensional diffusion (e.g. growth of grain boundary precipitates for which the rate determining process is diffusion to the grain boundary) and for growth where the new product formed is a layer on an existing particle, with the layer being thin relative to that existing particle. In the extended volume concept the superposition of the two types of growing nuclei of the same phase (e.g. growing on grain/subgrain boundaries and on particles) is readily incorporated by taking [62]:

$$
\alpha_{e x t}=\sum_{l} \alpha_{e x t, l}
$$

where $\alpha_{\text {ext }}$ is the extended volume achieved by formation of precipitates on sites of type $I$. In our case $I$ can be dispersoids and grain/subgrain boundaries, and hence $\alpha_{\text {ext }}=\left(k_{2,1} / \beta\right)^{n 1}+\left(k_{2,2} t\right)^{n 2}$, where $k_{2,1}$ and $k_{2,2}$ are the rate factors for the 2 formation processes, and $n_{1}$ and $n_{2}$ are their reaction exponents. Rather than using Eq. (7) it is more convenient to use the more flexible approximation $[38,69]$ 


$$
\alpha \cong 1-\left(\frac{\alpha_{e x t}}{\eta_{i}}+1\right)^{-\eta_{i}}
$$

where $\eta_{\mathrm{i}}$ is the impingement factor $[38,62]$. The latter equation has been verified to be applicable to diffusion controlled reactions in a wide range of works, incl. [70-73]. If $\eta_{i}$ is taken as 2 then the resulting equation closely approximates Eq (7) which is valid for randomly and homogeneously distributed nuclei, for which growth is not limited by blocking $[38,74]$. If nuclei are not randomly distributed, or if blocking of growth (for elongated particles) becomes involved, then $\eta$ । will decrease [38]. (See Section 6 for further discussion.)

\section{Illustration of model output}

To illustrate the model we will at this stage provide some of the predictions using the parameters provided in Table 2. Fig 9 shows the predicted $\mathrm{Zn}$ and $\mathrm{Mg}$ contents of the Al-rich matrix phase at the start of the quench, after the MTR and after the LTR for the AA7055 alloy. The reductions in alloy content are due to the formation of the $S\left(\mathrm{Al}_{2} \mathrm{CuMg}\right), \eta\left(\mathrm{Mg}(\mathrm{Zn}, \mathrm{Cu}, \mathrm{Al})_{2}\right)$ and $\mathrm{Zn}, \mathrm{Cu}$ rich thin plate phases/structures. At the high cooling rates $(>10 \mathrm{~K} / \mathrm{s}$ ) the precipitates are predominantly $\mathrm{Zn}$, Cu rich thin plate precipitates and $\eta\left(\mathrm{Mg}(\mathrm{Zn}, \mathrm{Cu}, \mathrm{Al})_{2}\right)$ on grain boundaries. (To aid transparency in Fig. 9, composition data after the HTR is not shown.)

\section{Thermal activation of the reactions and their activation energies}

The activation energy for $\mathrm{S}-\mathrm{Al}_{2} \mathrm{CuMg}$ formation, which occurs at high temperature where the vacancy concentration should be close to equilibrium, is taken as the activation energy for diffusion of the slowest diffusion element, which is $\mathrm{Cu}$. The activation energy is $140 \mathrm{~kJ} / \mathrm{mol}$ (see eg [75]). In a first attempt the activation energy for formation of the $\eta$ phase (MTR) was taken as the activation energy for Mg or Si diffusion in $\mathrm{Al}$ (both $\sim 120 \mathrm{~kJ} / \mathrm{mol}$ ), but this produces results that are clearly inconsistent with the present data and this activation energy is also inconsistent with kinetic data on this reaction from TTT diagrams in [19] and transformation data in [76], which both indicate activation energies that are at least a factor 2 lower. It appears that the diffusion is either determined by excess vacancies which possess 
an activation energy for migration of $59 \mathrm{~kJ} / \mathrm{mol}$ [77] or is due to diffusion occurring on subgrain boundaries and dislocations generated around misfitting particles. These defects substantially enhance diffusion [78]. We decided to obtain the activation energy for the diffusion process that governs formation of the $\eta$ phase (i.e. the MTR) in a AA7150 alloy from the DSC data for the exothermic reaction in the corresponding temperature range in [79]. To this end the Type B-1.92 method for activation energy analysis [80] was applied on peak temperatures reported in [79], which produced $E_{D}(M T R)=$ $60 \mathrm{~kJ} / \mathrm{mol}$ (using only heating rates at which the reaction is clearly visible).

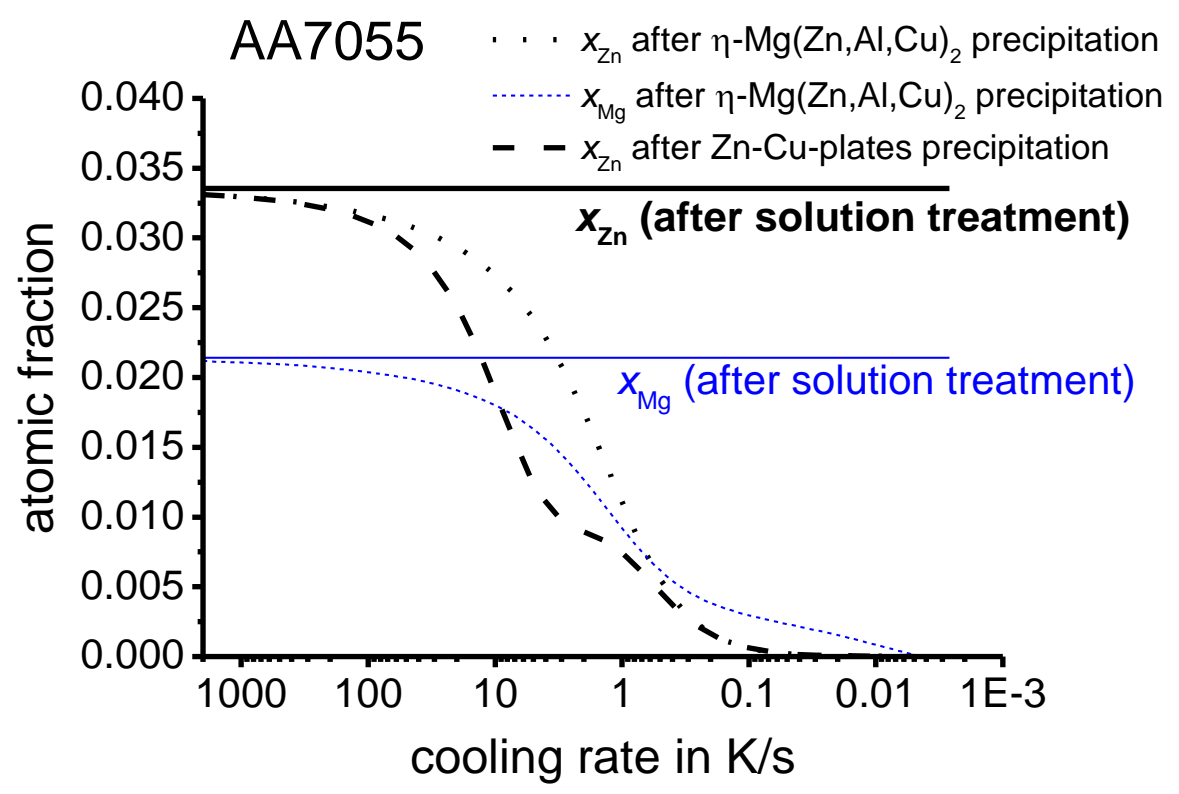

Fig. 9: Predicted $\mathrm{Zn}$ and Mg contents of the Al rich matrix phase at the start of the quench, after the MTR and after the LTR for the AA7055 alloy.

It is well known that at the low temperatures at which the LTR occurs, diffusion rates of alloying elements such as $\mathrm{Zn}$ in the presence of an equilibrium concentration of vacancies are much too low to allow any significant diffusion. TEM analysis of $\mathrm{Zn}, \mathrm{Cu}$-rich thin plate precipitates (LTR) shows that formation is associated with vacancy aggregates (nanovoids), suggesting the precipitation reaction occurs in the presence of a large supersaturation of vacancies. Thus the activation energy for this reaction should be dominated by vacancy diffusion, and it is thus taken as the activation energy for 
vacancy diffusion in Al: $E_{D}(L T R)=60 \mathrm{~kJ} / \mathrm{mol}$. This activation energy is comparable to the activation energy of $57 \mathrm{~kJ} / \mathrm{mol}$ for GP zone formation in a fast quenched $\mathrm{Al}-10 \mathrm{Zn}-0.1 \mathrm{Mg}$ alloy as determined in [81] from experiments performed at 0 to $40^{\circ} \mathrm{C}$.

\subsection{A model for strength/hardness of alloys artificially aged after cooling}

Generally a good correlation exists between yield strength and hardness for 7xxx alloys [82], but the presence of a substantial density of non-shearable dispersoid particles and grain and subgrain boundaries in commercial $7 x x x$ alloys will cause a deviation from linearity through their influence on strain hardening $[28,83,84]$. Hence we will adopt a two-term strength to hardness conversion, which is given by $[28,85]$ :

$$
\begin{aligned}
H V & =C_{\sigma-H V}\left(\sigma_{0.2}+K \sqrt{\varepsilon_{e f f}}\right) \\
K & =\left(0.35 G_{m}\left(f_{r} \sqrt{\frac{b}{d_{r g}}}+\left(1-f_{r}\right) \sqrt{\frac{b}{d_{s g}}}\right)+0.25 G_{m} \sqrt{\frac{b f_{n s, 1}}{2 r_{n s, 1}}+\frac{b f_{n s, 2}}{2 r_{n s, 2}}}\right)
\end{aligned}
$$

where $f_{\mathrm{r}}$ is the fraction of the material that is recrystallised, $d_{\mathrm{rg}}$ is the grain size in the recrystallised zones, $d_{\mathrm{sg}}$ is the subgrain size (in the unrecrystallised zones), $f_{\mathrm{ns}, \mathrm{i}}$ is the volume fraction of nonshearable particles of type $\mathrm{i}, r_{\mathrm{ns}, \mathrm{i}}$ is the average radius of non shearable particles, $G$ is the shear modulus, $C_{\mathrm{s}-\mathrm{HV}}$ is the conversion parameter (see below) and $\varepsilon_{\text {eff }}$ is the effective strain during hardness testing, taken as $0.08 . C_{\text {s-HV }}$ is fitted using $\mathrm{HV}$ and $\sigma_{0.2}$ data pairs for $\mathrm{AA7xxx}$ alloys from the literature.

To predict the yield strength based on the microstructure, the model by Starink and Wang [86] is adopted. As that model did not incorporate the strengthening due to dislocations generated due to misfitting particles, we will add that here to the model. For strength predictions in the artificially aged state we will take the maximum yield strength predicted by the model, with the exception of the AA7020 and AA7085 alloy where the $24 \mathrm{~h} / 120 \mathrm{C}$ treatment applied will lead to a slightly underaged condition [87]. We take this into account in the predictions. 
The model is designed for alloys with significant $\mathrm{Zn}$ and $\mathrm{Mg}$ content. Hence we will not produce strength predictions for cases where the ratio $\mathrm{X}_{\mathrm{Mg}}: \mathrm{X}_{\mathrm{Zn}}$ is larger than 5 or below 0.2 . This is the case for

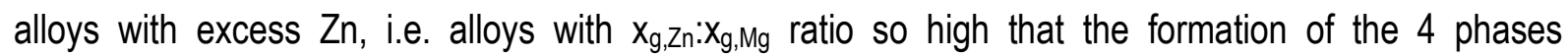
considered can not remove all $\mathrm{Zn}$ from solid solution even at extremely low quench rates. Such issues can be resolved by considering a fifth phase which would be a $\mathrm{Zn}$-rich phase, possibly $\mathrm{Zn}_{11} \mathrm{Mg}_{2}$, but this is out of the scope of the present work.

\section{Model parameters and predictions}

\subsection{Model parameters}

The model parameters used are presented in Table 2, and they include the values identified in Section 4. Some model parameters require further discussion.

There is no prior data available on the enthalpy of formation of the $\mathrm{Zn}, \mathrm{Cu}$-rich thin plate precipitates formed in the LTR. We can estimate it from the DSC data by considering that for phases for which any differences in entropy between the phases are much smaller than the enthalpy, the ratio of solvus temperature to enthalpy of formation is approximately constant. (For instance, this holds well for the $\theta$, $\theta^{\prime}$ and Guinier-Preston structures in Al-Cu alloys [88].) We obtained the solvus temperatures for the phases involved in the LTR and the MTR, $T_{\mathrm{s}, \mathrm{LTR}}$ and $T_{\mathrm{s}, \mathrm{MTR}}$, from hDSC thermograms for 5 alloys aged at a temperature that is above the solvus for $\mathrm{GPI}$ zones $\left(\sim 150^{\circ} \mathrm{C}\right.$, see [89]). For this treatment we selected an ageing temperature of $172{ }^{\circ} \mathrm{C}$; and we took $T_{\mathrm{s}, \mathrm{LTR}}$ as the maximum temperature of the first endothermic effect for alloys aged up to $16 \mathrm{~h}$. (Choosing the maximum for a range of treatments is appropriate because the transformation to $\eta^{\prime}$ and/or $\eta$ during the DSC heating or during ageing will influence this measurement of $T_{\mathrm{s}, \mathrm{LTR}}$ and we need to have the value most representative of $\mathrm{Zn}, \mathrm{Mg}$-rich precipitates in a fully formed state.) (Selected hDSC thermograms of these alloys were present in [31]). The data presented in Table 3 confirms the present analysis through showing a consistent $T_{\mathrm{s}, \mathrm{LTR}} / T_{\mathrm{s}, \mathrm{MTR}}$ for all 5 alloys, providing $\Delta H_{\mathrm{LTR}}=\Delta H_{\eta} T_{\mathrm{S}, \mathrm{LTR}} / T_{\mathrm{S}, \mathrm{MTR}}=12.8 \mathrm{~kJ} / \mathrm{mol}$. This value is adopted in the model and is seen (see below) to provide a good correspondence with measured enthalpies from cDSC. 
The grain size, sub grain size and recrystallized fractions were taken from EBSD and optical microstructure investigations of the alloys.

Table 2: Parameters in the model.

\begin{tabular}{|c|c|c|}
\hline Parameter & Value & Notes / Source \\
\hline \multicolumn{3}{|c|}{ General parameters } \\
\hline$b$ & $2.84 \times 10^{-10} \mathrm{~m}$ & \\
\hline \multicolumn{3}{|c|}{ HTR 1: S formation, fixed composition $\mathrm{Al}_{2} \mathrm{CuMg}$} \\
\hline$\eta_{\mathrm{i}}$ & 2 & $\begin{array}{l}\text { From model for diffusion controlled formation of homogeneously distributed } \\
\text { precipitates [5] }\end{array}$ \\
\hline$k_{o}$ & $5 \times 10^{20}$ & From fit to data \\
\hline$n$ & $1 / 2$ & According to model for diffusion controlled reactions [5] \\
\hline $\begin{array}{l}E_{\mathrm{D}} \\
\Delta H_{\mathrm{A} 2 \mathrm{CuMg}}\end{array}$ & $\begin{array}{l}140 \mathrm{~kJ} / \mathrm{mol} \\
19.8 \mathrm{~kJ} / \mathrm{mol}\end{array}$ & $\begin{array}{l}\text { Activation energy for diffusion of } \mathrm{Cu} \text { in } \mathrm{Al} \text {, the slowest diffusion element [75] } \\
\text { From solvus data in [90] }\end{array}$ \\
\hline \multicolumn{3}{|c|}{$\begin{array}{r}\text { HTR 2: } \beta \mathrm{Mg}_{2} \mathrm{Si} \text { formation, fixed composition } \mathrm{Mg}_{2} \mathrm{Si} \\
\text { All parameters adop }\end{array}$} \\
\hline \multicolumn{3}{|c|}{ MTR: $\eta-M g(Z n, C u, A l)_{2}$ phase, of units of $\mathrm{Mg}_{4} Z n_{8}$ and $\mathrm{Al}_{1} \mathrm{Zn}_{5} \mathrm{Cu}_{2} \mathrm{Mg}_{4}$} \\
\hline$\eta_{\mathrm{i}}$ & $1.2-1.7$ & $\begin{array}{l}\text { From model for diffusion controlled formation of inhomogeneously } \\
\text { distributed precipitates [38] }\end{array}$ \\
\hline$k_{0}$ & $3 \times 10^{10}$ & $\begin{array}{l}\text { From fit to data } \\
\text { For formation on grain boundaries, following the model for diffusion }\end{array}$ \\
\hline$n_{1}$ & $1 \frac{1}{2}$ & $\begin{array}{l}\text { controlled reactions }[5] \\
\text { For formation on dispersoids, following the model for diffusion controlled } \\
\text { reactions [5] }\end{array}$ \\
\hline$E_{\mathrm{D}}$ & $60 \mathrm{~kJ} / \mathrm{mol}$ & $\begin{array}{l}\text { Activation energy for diffusion of } \mathrm{Mg} \text { in } \mathrm{Al} \text { in the presence of excess } \\
\text { vacancies }[91,92]\end{array}$ \\
\hline $\begin{array}{l}\Delta H_{\mathrm{MgZn2}} \\
\Delta H_{\mathrm{Al1Zn5Cu2Mg}}\end{array}$ & $12.4 \mathrm{~kJ} / \mathrm{mol}$ & $\begin{array}{l}\text { Average of COST } 507 \text { database has }(11.8 \mathrm{~kJ} / \mathrm{mol} \text { [93]) and value obtained } \\
\text { by } 1^{\text {st }} \text { principles modelling }(12.9 \mathrm{~kJ} / \mathrm{mol}[7]) \text {. }\end{array}$ \\
\hline 4 & $1.35 \mathrm{x} \Delta H_{\mathrm{MgZn} 2}$ & From $1^{\text {st }}$ principles modelling [7] \\
\hline \multicolumn{3}{|c|}{ LTR: $\mathrm{Zn}-\mathrm{Cu}$ rich platelet phase } \\
\hline$\eta_{\mathrm{i}}$ & 2 & According to model for diffusion controlled reactions [5] \\
\hline$k_{0}$ & $7 \times 10^{5}$ & From fit to data \\
\hline$n$ & $1 \frac{1}{2}$ & $\begin{array}{l}\text { Following the model for diffusion controlled reactions [5] } \\
\text { Activation energy for diffusion of } \mathrm{Mg} \text { in } \mathrm{Al} \text { in the presence of excess }\end{array}$ \\
\hline $\begin{array}{l}E_{\mathrm{D}} \\
\Delta H_{\mathrm{LTR}}\end{array}$ & $\begin{array}{l}60 \mathrm{~kJ} / \mathrm{mol} \\
12.8 \mathrm{~kJ} / \mathrm{mol}\end{array}$ & $\begin{array}{l}\text { vacancies }[91,92] \\
\text { See text }\end{array}$ \\
\hline \multicolumn{3}{|c|}{ Strength model } \\
\hline$M_{\text {(for tensile tests }}$ & & \\
\hline in L direction) & 2.73 & $\begin{array}{l}\text { For tensile tests in the longitudinal direction, see [94] } \\
\text { For all other tensile and hardness tests; obtained from self-consistent }\end{array}$ \\
\hline $\begin{array}{l}M_{\text {(all other tests) }} \\
G\end{array}$ & $\begin{array}{l}2.6 \\
27 \mathrm{GPa}\end{array}$ & models [95], see also [96] \\
\hline
\end{tabular}


Table 3: Analysis of hDSC curves of 5 alloys.

\begin{tabular}{l|c|c|c|c} 
Alloy & $\begin{array}{c}T_{\mathrm{s}, \mathrm{MTR}} \\
\left({ }^{\circ} \mathrm{C}\right)\end{array}$ & $\begin{array}{c}T_{\mathrm{s}, \mathrm{LTR}} \\
\left({ }^{\circ} \mathrm{C}\right)\end{array}$ & $T_{\mathrm{s}, \mathrm{MTR}} / T_{\mathrm{s}, \mathrm{LTR}}$ & $\begin{array}{c}\Delta H_{\mathrm{LTR}} \\
(\mathrm{J} / \mathrm{mol})\end{array}$ \\
\hline AA7150m & 425 & 240 & 1.42 & 12,725 \\
\hline AA7150hiZn & 430 & 231 & 1.44 & 12,583 \\
\hline AA7150loCu & 404 & 230 & 1.42 & 12,719 \\
\hline AA7150hiCu & 400 & 239 & 1.38 & 13,144 \\
\hline AA7150hiZnCu & 405 & 232 & 1.40 & 12,914
\end{tabular}

The impingement parameter $\eta_{\mathrm{i}}$ for the HTR and LTR is taken as 2 (i.e. such that impingement closely approximates the model in [5]); for the MTR $\eta_{\mathrm{i}}$ is predicted considering the dispersoid density using the approach in [10] and calculated using the procedure in [38]. The density of the phases was obtained from data in [51,97-99].

We also wish to consider the effect of interface energy of the dispersoid particles on the nucleation rate, however to the best of our knowledge there is no data available on the interfacial energies of the various dispersoids and the matrix. It is known however that the interfaces of $\mathrm{Al}_{3} \mathrm{Zr}$ and $\mathrm{Al}_{6}(\mathrm{Mn}, \mathrm{Fe})$ are semi-coherent with the matrix, whilst the $\mathrm{Cr}$ containing dispersoids are generally considered to be incoherent. Typically the difference in interfacial energy between a semi coherent precipitate (misfit $\sim 1 \%$ ) and an incoherent interface is about a factor 3 to 8 [100]. In line with this we take the efficiency of $\mathrm{Cr}$ containing dispersoids in nucleating the $\eta-\mathrm{Mg}(\mathrm{Zn}, \mathrm{Al}, \mathrm{Cu})_{2}$ precipitates to be a factor 5 larger than that of the semi coherent precipitates. This assumption has no effect on the accuracy of the model for the present alloys for which nucleation of quenched-in precipitates is dominated by $\mathrm{Al}_{3} \mathrm{Zr}$ dispersoids, grain/subgrain boundaries, and, to a lesser extent, Mn containing dispersoids. It does influence the accuracy of predicting data on $\mathrm{Cr}$ containing alloys.

\subsection{Model predictions}

We first provide additional verification that the model for alloys age hardened after a fast water quench is accurate. For this we considered yield strength data on 20 alloys; including yield strength data 
on peak aged and overaged conditions of our AA7449 alloy, data on our AA7150 reported previously [101] and on 18 alloys reported before in [86]. Taken together these 20 alloys cover the range 2.23.7 at $\% \mathrm{Zn}, 2.0-3.1 \mathrm{at} \% \mathrm{Mg}, 0.5-1.3 \mathrm{at} \% \mathrm{Cu}$, with data generated both before and after the model [86] was published. As seen in Fig. 10, the model predicts the measured yield strengths very well.

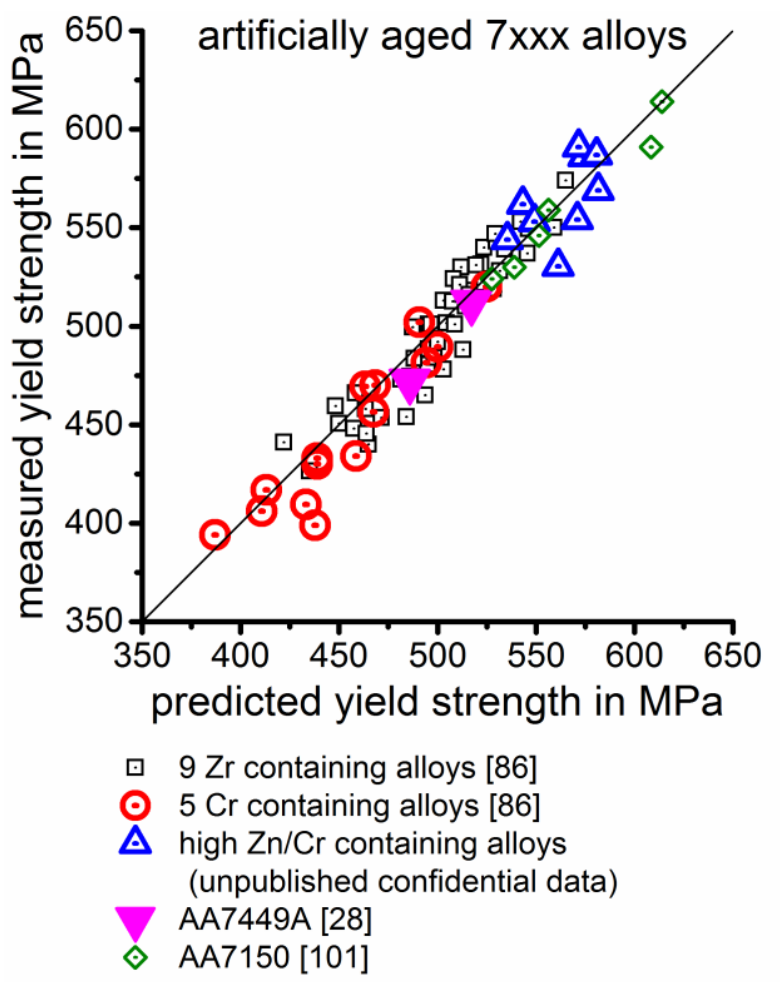

Fig. 10: Measured and predicted yield strength of 20 water quenched and subsequently artificially aged Al-Zn-Mg-Cu based alloys.

In Fig 11 the model predictions for $\Delta H$ and hardness are compared with measured data. The error bars of the measured enthalpy changes show estimated uncertainties of $\pm 10 \%$ for the total enthalpy change and $\pm 30 \%$ for the enthalpy change of the LTR. The uncertainty mainly is caused by the evaluation procedure and the larger value for the LTR results from an increased influence of the zero level correction at the low temperatures (compare [12]). The error bars on the hardness show the standard deviation out of six indentations. For AA7049A besides conventional cDSC also differential fast scanning chip calorimetry results are provided (see [18]). For this alloy only cooling rates larger than $3 \mathrm{~K} / \mathrm{s}$ are considered, because at slower cooling rates strong overlapping of the HTR and MTR occurs [18], which cannot be captured by our model which assumes consecutive reactions. The figures show 
an excellent correspondence with the data, encompassing a total of $\sim 200$ measured yield strength and $\Delta H$ values for a wide range of cooling rates and compositions. This is achieved by fitting 4 parameters, with all the other parameters determined from theory and assessment above. The 4 parameters are the initial rates of formation of the 4 types of precipitates: $\mathrm{S}-\mathrm{Al}_{2} \mathrm{CuMg}$ phase, $\eta-\mathrm{Mg}(\mathrm{Al}, \mathrm{Cu}, \mathrm{Zn})_{2}$ formation on grain boundaries, $\eta$ - $\mathrm{Mg}(\mathrm{Al}, \mathrm{Cu}, \mathrm{Zn})_{2}$ formation on dispersoids and the $\mathrm{Zn}$-Cu-rich platelets.

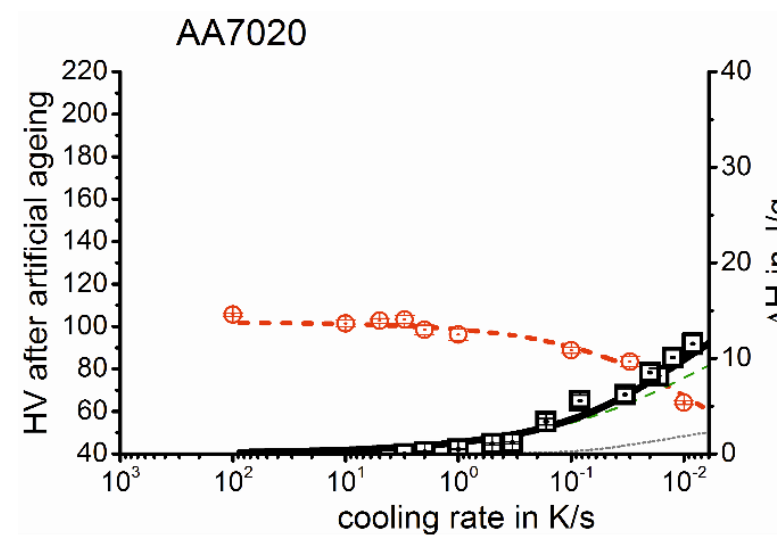

AA7085

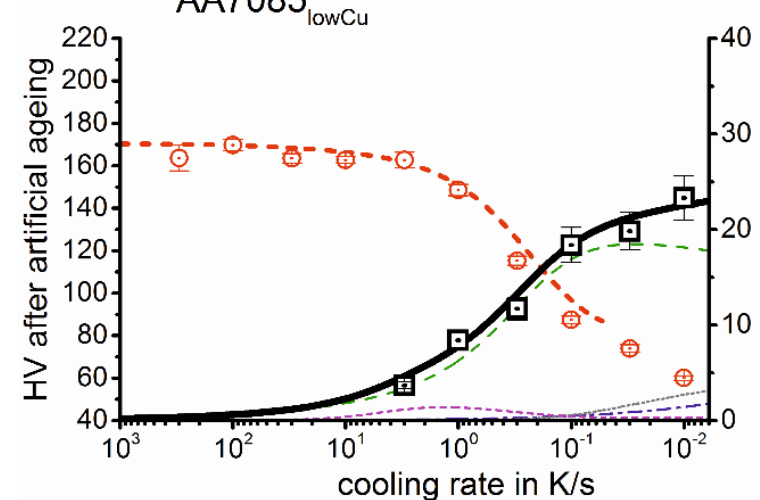

AA7150

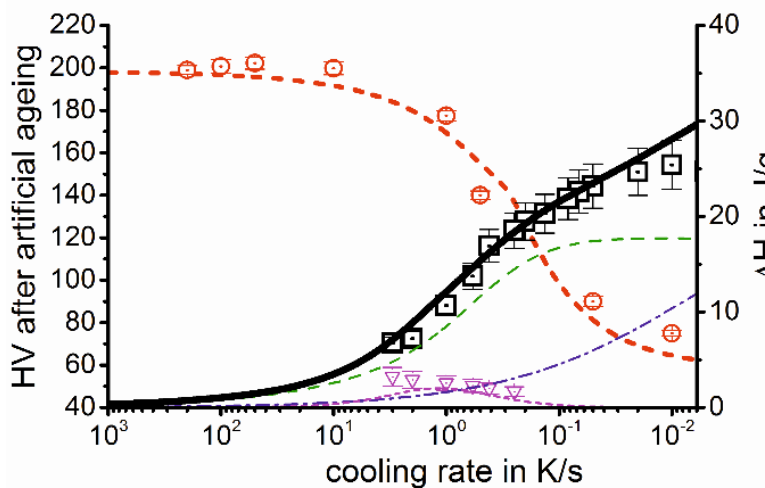

AA7055

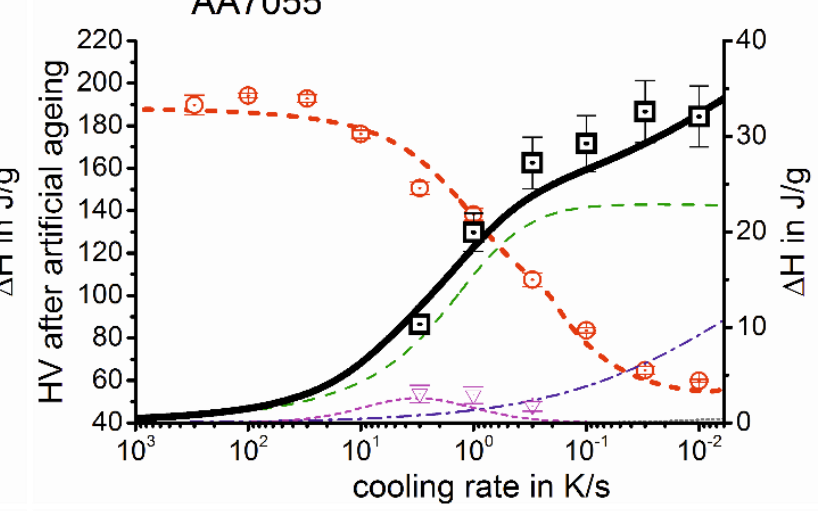

AA7085
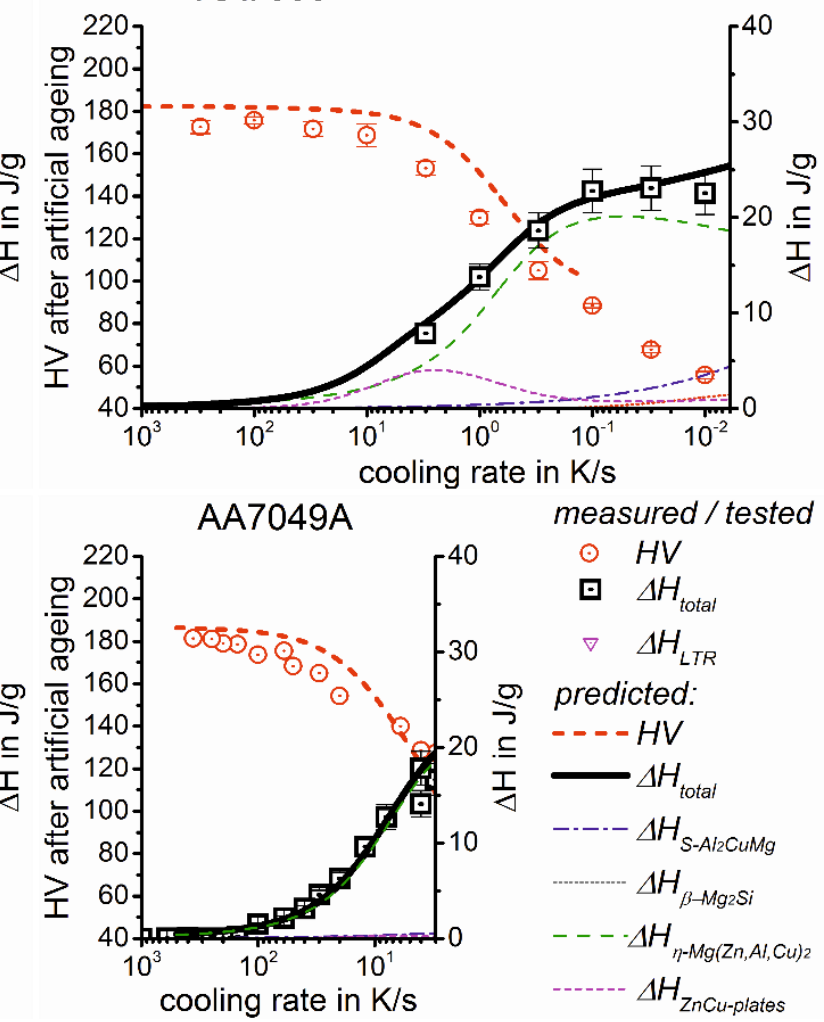

Fig. 11: $\Delta H$ and hardness as a function of the cooling rate for 6 alloys. Both, measured values (from CDSC and Vickers hardness tests) as well as model predictions (from the model in section 4) are provided. 


\section{Discussion}

\subsection{Model efficiency and model limitations}

TEM data obtained in a range of works indicate that $\eta-\mathrm{Mg}(\mathrm{Zn}, \mathrm{Al}, \mathrm{Cu})_{2}$ phase forms before $\mathrm{T}-\mathrm{Al}_{2} \mathrm{Mg}_{3} \mathrm{Zn}_{3}$ phase formation. This is notwithstanding the fact that various assessments of the $\mathrm{Al}-\mathrm{Mg}-\mathrm{Zn}$ phase diagram indicate that for alloys with $\mathrm{Zn}$ and $\mathrm{Mg}$ contents similar to these alloys, only $\mathrm{T}-\mathrm{Al}_{2} \mathrm{Mg}_{3} \mathrm{Zn}_{3}$ is a stable phase $[46,102]$. It is thought that the reason for this is that $\eta-\mathrm{Mg}(\mathrm{Zn}, \mathrm{Al}, \mathrm{Cu})_{2}$ has a higher $\mathrm{Zn}: \mathrm{Mg}$ ratio than $\mathrm{T}-\mathrm{Al}_{2} \mathrm{Mg}_{3} \mathrm{Zn} \mathrm{n}_{3}$ phase with $\mathrm{Zn}$ diffusing faster than $\mathrm{Mg}$. Thus $\eta-\mathrm{Mg}(\mathrm{Zn}, \mathrm{Al}, \mathrm{Cu})_{2}$ should form faster, and as the 2 reactions compete for the same alloying elements, the faster reaction suppresses the other reaction. Hence, the model includes formation of the $\eta-\mathrm{Mg}(\mathrm{Zn}, \mathrm{Al}, \mathrm{Cu})_{2}$ phase, and to keep the model transparent and avoid including reactions that have no direct industrial relevance $\mathrm{T}-\mathrm{Al}_{2} \mathrm{Mg}_{3} \mathrm{Zn}_{3}$ phase is not included. The model nevertheless achieves good accuracies in predicting enthalpy changes and artificially aged hardness at medium to high cooling rates and therefore particularly in the industrially relevant cooling/quenching treatments. Apparently any limited $\mathrm{T}$ phase formation that might occur does generally not significantly influence the precipitation in terms of enthalpy and resulting artificially aged strength.

It was found that for the Mn containing AA7150 commercial alloy a near perfect fit to cDSC enthalpy data could be obtained by applying Eq. (7), which is valid for a random and homogeneous distribution of nuclei, whilst the overall fit of the model to all alloys including the Mn free alloys was slightly better when variation of nuclei density due to dendritic segregation of dispersoid forming elements was considered and Eq. (10) with $\eta_{i}=1.3 \pm 0.2$ was used. This finding is consistent with the known inverse segregation behaviour of $\mathrm{Mn}$ and $\mathrm{Zr}$ : a combination of $\mathrm{Zr}$ and $\mathrm{Mn}$ will produce a more homogeneous distribution of dispersoids, which is beneficial for the mechanical properties by virtue of reducing recrystallization [103-105]. (Provided optimised Zr and Mn contents are used.) This suggest that a further improvement over the already very accurate model can be obtained by including the inhomogeneous distribution of dispersoids in the model. To maintain the model efficiency and avoid full 
3D modelling of $\eta-\mathrm{Mg}(\mathrm{Al}, \mathrm{Zn}, \mathrm{Cu})_{2}$ precipitation, Eq. (10) with $\eta_{\mathrm{i}}$ determined from the assessment in [38] would then be needed.

The present model formulation is highly efficient and very successful in predicting quench sensitivity and strength of a wide range of alloys, but there is a limitation to its range of validity. The model particularly becomes invalid at the very slow cooling rates in the stage where $\mathrm{Zn}: \mathrm{Mg}$ ratios in the matrix change to the extent that the reactions considered here $\left(\mathrm{S}, \mathrm{Mg}_{2} \mathrm{Si}, \eta\right.$ and the $\mathrm{Zn}, \mathrm{Cu}$ rich thin plate precipitates) are no longer the main precipitates that form. Thermodynamic models (Thermocalc TCAL2) in [25] show that this is particularly the case for conditions where the $\mathrm{Zn}: \mathrm{Mg}$ ratio reduces to below $\sim 0.95$ at which the $\mathrm{T}-\mathrm{Al}_{2} \mathrm{Mg}_{3} \mathrm{Zn} \mathrm{n}_{3}$ phase becomes a stable phase, progressively replacing the $\eta$ phase as the $\mathrm{Zn}: \mathrm{Mg}$ ratio drops further. Under those conditions the model can not accurately predict the amount of $\mathrm{Mg}$ and $\mathrm{Zn}$ in the Al-rich matrix phase after cooling and we thus will not apply the strength model in those situations.

It is noted that duplex ageing or slow heating to the ageing temperature can recover some of the hardness/strength losses of $\mathrm{Al}-\mathrm{Zn}-\mathrm{Mg}$ based alloys that are quenched at rates that reduce the aged yield strength by about 20 to $60 \%$ when a single stage artificial ageing treatment is used $[22,106,107]$. We hope to implement this effect in a future version of the model.

\subsection{Further model predictions}

With the model established we can now make predictions on quench sensitivity as a function of alloy composition. In Fig 12 predictions for the peak aged proof strength and amount of $\eta-\mathrm{Mg}(\mathrm{Zn}, \mathrm{Al}, \mathrm{Cu})_{2}$ formation for 3 alloys which have an increasing $\mathrm{Zn}$ and $\mathrm{Mg}$ content and constant $\mathrm{Zn}: \mathrm{Mg}$ ratio are provided. The figure shows the expected increase of strength with increasing alloying content and also shows that quench sensitivity with respect to the proof strength increases with increasing alloying content. Alloys with higher $\mathrm{Zn}$ and $\mathrm{Mg}$ content have more $\eta-\mathrm{Mg}(\mathrm{Zn}, \mathrm{Al}, \mathrm{Cu})_{2}$ formed, which at the higher cooling rates will be predominantly on grain boundaries. This will also cause a lower toughness. 


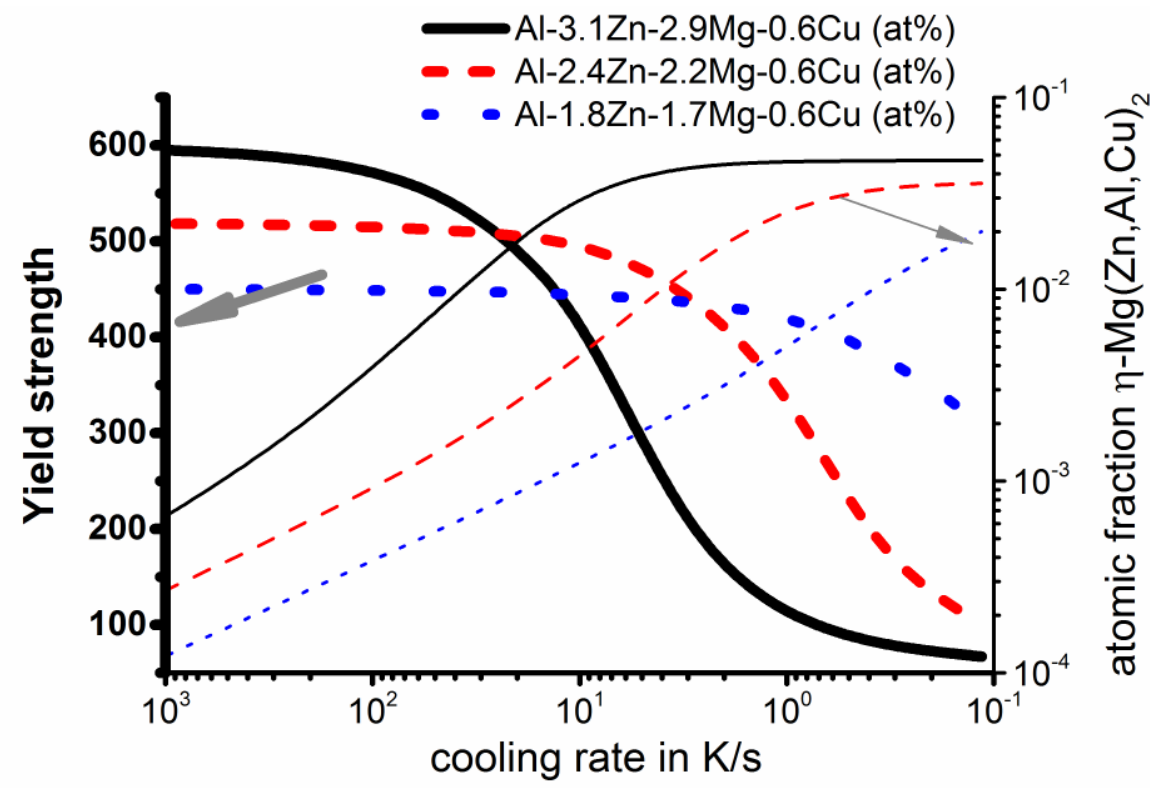

Fig. 12: Influence of quench rate on yield strength and amount of $\eta-\mathrm{Mg}(\mathrm{Zn}, \mathrm{Al}, \mathrm{Cu})_{2}$ for 3 alloys with varying increasing $\mathrm{Zn}$ and $\mathrm{Mg}$ content and constant $\mathrm{Zn}: \mathrm{Mg}$ ratio. $\left(\mathrm{x}_{\mathrm{g}, \mathrm{Cu}}=0.6 \mathrm{at} \%, \mathrm{x}_{\mathrm{g}, \mathrm{Zr}}=0.04 \mathrm{at} \%\right)$. The proof strength throughout is predicted for the artificially aged condition, i.e. no stretching prior to ageing for $24 \mathrm{~h}$ at $120^{\circ} \mathrm{C}$.

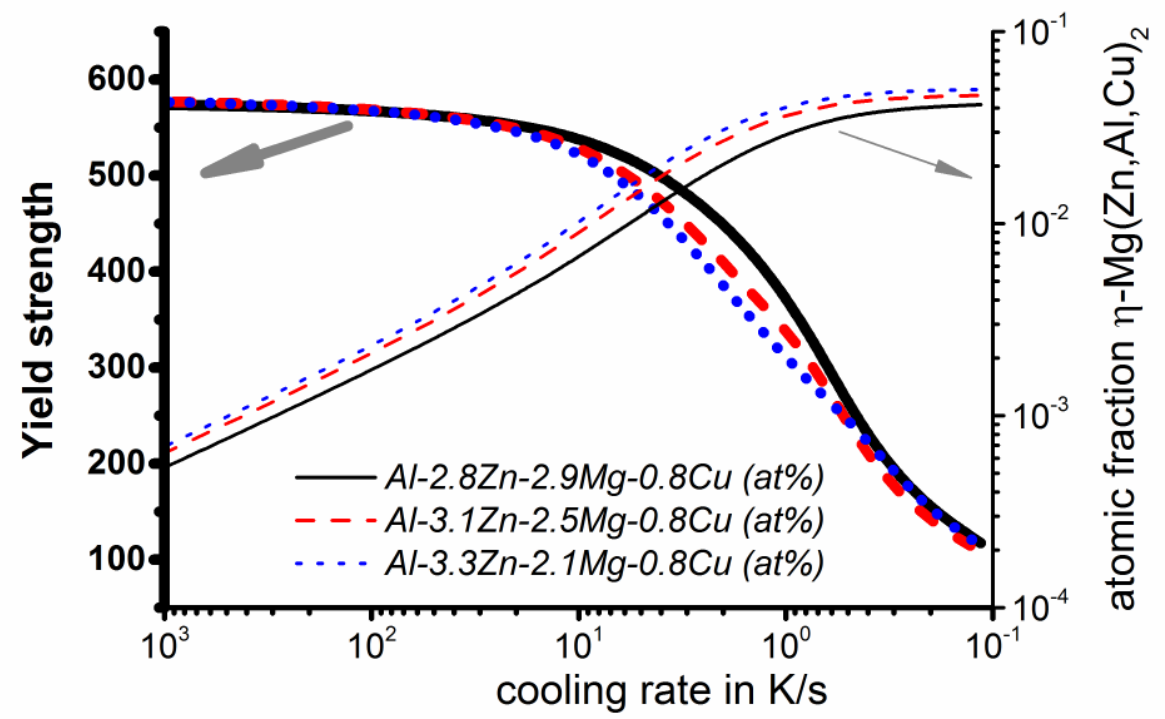

Fig. 13: Influence of quench rate on proof strength and amount of $\eta-\mathrm{Mg}(\mathrm{Zn}, \mathrm{Al}, \mathrm{Cu})_{2}$ for 3 alloys with $\mathrm{xg}_{\mathrm{g}, \mathrm{Cu}}=0.8$ at $\%, \mathrm{x}_{\mathrm{g}, \mathrm{Zr}}=0.04$ at $\%$ and varying $\mathrm{Mg}$ and $\mathrm{Zn}$ contents that produce identical strength in water quenched conditions. ( $f_{\text {rec }}$ is taken as 0.1 ).

Fig 13 shows predictions for the peak aged proof strength and amount of $\eta-M g(Z n, A l, C u)_{2}$ formation for 3 alloys with $\mathrm{Mg}$ and $\mathrm{Zn}$ chosen such that they have a near identical strength when quenched at a cooling rate of $\sim 40 \mathrm{~K} / \mathrm{s}$ followed by artificial ageing. (A cooling rate of $\sim 40 \mathrm{~K} / \mathrm{s}$, is typically 
achieved for a $25 \mathrm{~mm}$ plate, quenched in cold water [108]). The data indicates that the alloy with the high $\mathrm{Zn}: \mathrm{Mg}$ ratio has the higher quench sensitivity due to the higher amounts of $\eta-\mathrm{Mg}(\mathrm{Zn}, \mathrm{Al}, \mathrm{Cu})_{2}$ formed, although for $\mathrm{Zn}: \mathrm{Mg}$ ratio > 1.2 further degradation of quench sensitivity is limited. For this cooling rate (typical of a $25 \mathrm{~mm}$ plate), the plate with the higher $\mathrm{Zn}: \mathrm{Mg}$ ratio has more $\eta-\mathrm{Mg}(\mathrm{Zn}, \mathrm{Al}, \mathrm{Cu})_{2}$ formed on grain boundaries and is thus expected to have a lower toughness.

\section{Conclusions}

A model for precipitation reactions during cooling of Al-Zn-Mg-Cu-Mn-Zr based alloys and their strength after an artificial ageing treatment is derived and verified through an extensive set of cooling experiments on 6 alloys (plus additional experiments on six further alloys). The DSC, TEM and SEM data shows that the reactions during quenching are dominated by four different reactions: a high temperature reaction (typically $\sim 450^{\circ} \mathrm{C}$ down to $\sim 350{ }^{\circ} \mathrm{C}$ ) due mostly to $\mathrm{S}-\mathrm{Al}_{2} \mathrm{CuMg}$ phase formation (alternatively $\mathrm{Mg}_{2} \mathrm{Si}$ in the absence of $\mathrm{Cu} /$ presence of $\left.\mathrm{Si}\right)$, a medium temperature reaction $\left(\sim 350^{\circ} \mathrm{C}\right.$ down to $\left.\sim 250^{\circ} \mathrm{C}\right)$ due predominantly to $\eta-\mathrm{Mg}(\mathrm{Zn}, \mathrm{Al}, \mathrm{Cu})_{2}$ phase formation and a lower temperature reaction $\left(\sim 250^{\circ} \mathrm{C}\right.$ down to $\left.\sim 150^{\circ} \mathrm{C}\right)$ due to a $\mathrm{Zn}$-Cu rich thin plate phase. The model provides accurate predictions of enthalpy changes and hardness / strength of the alloys for a wide range of cooling rates and compositions incorporating the range of commercially important alloys and cooling rates. The quench sensitivity is predicted to increase with increasing content of main alloying elements $(\mathrm{Zn}, \mathrm{Mg}$, $\mathrm{Cu}$ ), increasing fraction recrystallised, increasing number of dispersoid particles, increasing surface: volume ratio of dispersoid particles and increasing dispersoid/matrix incoherency. The present work makes a significant contribution towards understanding the mechanisms driving quench sensitivity of AlZn-Mg-Cu alloys and the derived model can be used for alloy design. 


\section{Appendix}

In the model the volume fractions of undissolved phases is calculated based on literature data and thermodynamic model predictions (e.g. in $[30,97]$ ), and as part of the aim of providing a computationally efficient model, some solubilities in the Al-rich phase are taken as zero and the number of phases considered is limited to the main ones observed in these alloys: $\mathrm{Al}_{6}(\mathrm{Mn}, \mathrm{Fe}), \mathrm{Al}_{3} \mathrm{Zr}, \mathrm{Al}_{7} \mathrm{Cu}_{2} \mathrm{Fe}, \mathrm{Al}_{18} \mathrm{Mg}_{3} \mathrm{Cr}_{2}$ and $\mathrm{Al}_{2} \mathrm{CuMg}$. The $\mathrm{Mn}$ and Fe solubility at the solution treatment temperature are effectively zero [97], and we consider that for the present compositions all $\mathrm{Mn}$ is present in the $\mathrm{Al}_{6}(\mathrm{Mn}, \mathrm{Fe})$ phase. The composition of the $\mathrm{Al}_{6}(\mathrm{Mn}, \mathrm{Fe})$ is assessed using thermodynamic modelling software. The $\mathrm{S}-\mathrm{Al}_{2} \mathrm{CuMg}$ phase amount is calculated on the basis of the solubility product in [30], and the $\mathrm{Cr}$ solubility at the solution treatment temperature is taken as 0.04 at $\%[30,109])$.

In the model the total particle-matrix interface area of dispersoid particles present at the start of the quench influences the nucleation of particles during the quench. For each dispersoid phase the total particle-matrix interface area is obtained by considering all particles of each phase have one typical shape, e.g. spherical for $\mathrm{Al}_{3} \mathrm{Zr}$, thin plate for $\mathrm{Al} 6 \mathrm{Mn}$ and cube for $\mathrm{Al}_{18} \mathrm{Mg}_{3} \mathrm{Cr}_{2}$, and the average size is obtained from data (primarily TEM) in the literature for alloys with dispersoid forming element contents and solution heat treatments that are similar to the present alloys $[25,55,56,110]$. At the present stage of model development, no attempt is made to predict any potential variations of size of dispersoid particles between alloys. 


\section{Acknowledgements}

We gratefully acknowledge Olaf Keßler (Materials Science, University of Rostock), Christoph Schick

(Polymer Physics, University of Rostock) for discussions on the DSC results. Martin Beck (Materials

Science, University of Rostock) and Davit Zohrabyan (formally University of Rostock) are acknowledged for performing some of the DSC and hardness experiments. Matthew Weyland of the Monash Centre for Electron Microscopy (Monash University) is acknowledged for his help in imaging the LTR platelet phase using the HRTEM. B.M. gratefully acknowledges the German Academic Exchange Service (DAAD) for funding his sabbatical year at the University of Southampton (DAAD-Postdoc-Program fellowship).

\section{References}

[1] Polmear IJ. Light alloys. 4th ed. Oxford: Butterworth-Heinemann; 2006.

[2] Morere B, Ehrström J, Gregson RJ, Sinclair I. Metall. Mater. Trans. A-Phys. Metall. Mater. Sci. 2000;31:250315.

[3] Zhang Y, Bettles C, Rometsch PA. J Mater Sci 2014;49:1709-15.

[4] Heinz A, Haszler A, Keidel C, Moldenhauer S, Benedictus R, Miller WS. Mater. Sci. Eng. A 2000;280:102-7.

[5] Starink MJ. Thermochim Acta 2014;596:109-19.

[6] Starink MJ. J. Alloy. Compd. 2015;630:250-5.

[7] Fang X, Song M, Li K, Du Y, Zhao D, Jiang C, Zhang H. J Mater Sci 2012;47:5419-27.

[8] Milkereit B, Starink MJ. Mater. Des. 2015;76:117-29.

[9] Zhang X, Liu W, Liu S, Zhou M. Mater. Sci. Eng. A 2011;528:795-802.

[10] Robson JD, Prangnell PB. Mater. Sci. Eng. A 2003;352:240-50.

[11]Zhang Y, Milkereit B, Kessler O, Schick C, Rometsch PA. J. Alloy. Compd. 2014;584:581-9.

[12] Osten J, Milkereit B, Schick C, Kessler O. Materials 2015;8:2830-48.

[13] Song F, Zhang X, Liu S, Tan Q, Li D. Corros. Sci. 2014;78:276-86.

[14] Robinson JS, Tanner DA, Truman CE, Paradowska AM, Wimpory RC. Mater Charact 2012;65:73-85.

[15] Deng Y, Wan L, Zhang Y, Zhang X. J. Alloy. Compd. 2011;509:4636-42.

[16] Park JK, Ardell AJ. MTA 1983;14:1957-65.

[17] Shuey RT, Tiryakioğlu M, Bray GH, Staley JT. MSF 2006;519-521:1017-22.

[18]Zohrabyan D, Milkereit B, Schick C, Kessler O. Trans. Nonferrous Met. Soc. China 2014;24:2018-24.

[19] Tiryakioğlu M, Robinson JS, Eason PD. Mater. Sci. Eng. A 2014;618:22-8.

[20] Lim ST, Eun IS, Nam SW. Mater. Trans. 2003;44:181-7.

[21] Shuey RT, Tiryakioğlu M, Bray GH, Staley JT. Toughness after interrupted quench, in: 10th International Conference on Aluminium Alloys, (ICAA-10). p. 519-521.

[22] Shuey RT, Tiryakioglu M. Quenching of Aluminum Alloys, in: Quenching Theory and Technology, CRC Press, 2nd edition, 2011.

[23] Rometsch PA, Zhang Y, Knight S. Trans. Nonferrous Met. Soc. China 2014;24:2003-17.

[24] Liu S, Liu W, Zhang Y, Zhang X, Deng Y. J. Alloy. Compd. 2010;507:53-61.

[25] Yong Zhang. Quench Sensitivity of 7xxx Series Aluminium Alloys. PhD thesis, Melbourne, Australia; 2014.

[26] Schloth P, Wagner JN, Fife JL, Menzel A, Drezet J, van Swygenhoven H. Appl. Phys. Lett. 2014;105.

[27] Patrick Schloth. Precipitation in the high strength AA7449 aluminium alloy: implications on internal stresses on different length scales. Lausanne; 2015 (PhD thesis, EPFL Lausanne, in press). 
[28] Kamp N, Sinclair I, Starink MJ. Metall. Mater. Trans. A-Phys. Metall. Mater. Sci. 2002;33:1125-36.

[29] Xu DK, Rometsch PA, Birbilis N. Mater. Sci. Eng. A 2012;534:234-43.

[30] Li X, Starink MJ. Mater. Sci. Technol. 2001;17:1324-8.

[31] Li XM, Starink MJ. J. Alloy. Compd. 2011;509:471-6.

[32] Ayer R, Koo JY, Steeds JW, Park BK. MTA 1985;16:1925-36.

[33] Sharma MM. Mater Charact 2008;59:91-9.

[34] Avrami M. J Chem. Phys. 1940;8:212-24.

[35] Kolmogorov AN. Izv. Akad. Nauk SSSR, Ser. Mat. 1937:355-9.

[36] Burbelko AA, Fraś E, Kapturkiewicz W. Mater. Sci. Eng. A 2005;413-414:429-34.

[37] Tomellini M. Thermochim Acta 2013;566:249-56.

[38] Starink MJ. J Mater Sci 2001;36:4433-41.

[39] Rometsch PA, Starink MJ, Gregson PJ. Mater. Sci. Eng. A 2003;339:255-64.

[40] Starink MJ, Gregson PJ. Mater. Sci. Eng. A 1996;211:54-65.

[41] Conserva M, Fiorini P. Metall Trans 1973;4:857-62.

[42] Deschamps A, Bréchet Y. Mater. Sci. Eng. A 1998;251:200-7.

[43] Deschamps A, Brechet Y. Scr. Mater. 1998;39:1517-22.

[44] Deschamps A, Texier G, Ringeval S, Delfaut-Durut L. Mater. Sci. Eng. A 2009;501:133-9.

[45] Liu S, Zhong Q, Zhang Y, Liu W, Zhang X, Deng Y. Mater. Des. 2010;31:3116-20.

[46] Liang P, Tarfa T, Robinson JA, Wagner S, Ochin P, Harmelin MG, Seifert HJ et al. Thermochim Acta 1998;314:87-110.

[47] Andrae D, Paulus B, Wedig U, Jansen M. Zeitschrift fur Anorganische und Allgemeine Chemie 2013;639:1963-7.

[48] Watson RE, Bennett LH. Acta Metall. 1982;30:1941-55.

[49] Fritz Laves, H. Witte. Metallwirtschaft 1936;15:840-2.

[50] Steurer W. Crystal Structures of Metallic Elements and Compounds, in: Hono, David E. LaughlinKazuhiro (Ed.). Physical Metallurgy (Fifth Edition). Oxford: Elsevier; 2014. p. 1-101.

[51] Wandahl G, Christensen AN, Uggerud E, Songstad J, Lönnberg H, Colacio E, Mulichak AM et al. Acta Chem. Scand. 1989;43:296-7.

[52] Engdahl T, Hansen V, Warren PJ, Stiller K. Mater. Sci. Eng. A 2002;327:59-64.

[53] Li Y, Kovarik L, Phillips PJ, Hsu Y, Wang W, Mills MJ. Philos Mag Lett 2012;92:166-78.

[54] Thompson DS, Subramanya BS, Levy SA. MTA 1971;2:1149-60.

[55] Starink MJ, Li XM. Metall. Mater. Trans. A-Phys. Metall. Mater. Sci. 2003;34 A:899-911.

[56] Li YJ, Zhang WZ, Marthinsen K. Acta Mater. 2012;60:5963-74.

[57] Kong BO, Nam SW. Mater Lett 1996;28:385-91.

[58] Kikuchi S, Yamazaki H, Otsuka T. J Mater Process Technol 1993;38:689-701.

[59] Rogl P, Stiltz S, Hayes FH. JPE 1992;13:317-23.

[60] Sten Samson. Acta Cryst. 1958;11:851-7.

[61] K. Little, H. J. Axon, W. Humerothery. J. Inst. Met. 1948;75:39-50.

[62] Starink MJ, Zahra AM. Philos. Mag. A-Phys. Condens. Matter Struct. Defect Mech. Prop. 1998;77:187-99.

[63] Dlubek G, Krause R, Brümmer O, Plazaola F. J Mater Sci 1986;21:853-8.

[64] Mukhopadhyay AK, Prasad KS. Philos Mag Lett 2011;91:214-22.

[65] Müller S, Wang L, Zunger A, Wolverton C. Phys. Rev. B Condens. Matter Mater. Phys. 1999;60:16448-62.

[66] Wolverton C. Acta Mater. 2001;49:3129-42.

[67] Cumbrera FL, Sánchez-Bajo F. Thermochim Acta 1995;266:315-30.

[68] Baker TA, Monti, O. L. A., Nesbitt DJ. J. Phys. Chem. C 2011;115:9861-70.

[69] Starink MJ. Int. Mater. Rev. 2004;49:191-226.

[70] Badji R, Kherrouba N, Mehdi B, Cheniti B, Bouabdallah M, Kahloun C, Bacroix B. Precipitation kinetics and mechanical behavior in a solution treated and aged dual phase stainless steel; 2014.

[71] Gao Q, Wang C, Qu F, Wang Y, Qiao Z. J. Alloy. Compd. 2014;610:322-30.

[72] Kianezhad M, Sajjadi SA. Metall. Mater. Trans. A-Phys. Metall. Mater. Sci. 2013;44:2053-9.

[73] Song SJ, Liu F, Zhang ZH. Acta Mater. 2014;64:266-81.

[74] Birnie III, D. P., Weinberg MC. J Chem. Phys. 1995;103:3742-6.

[75] Simonovic D, Sluiter, M. H. F. Phys. Rev. B Condens. Matter Mater. Phys. 2009;79.

[76] Liu S, Li C, Deng Y, Zhang X, Zhong Q. Met. Mater. Int. 2014;20:195-200.

[77] Ho G, Ong MT, Caspersen KJ, Carter EA. Phys. Chem. Chem. Phys. 2007;9:4951-66.

[78] Baker SP, Joo Y, Knauß MP, Arzt E. Acta Mater. 2000;48:2199-208.

[79] Ghosh KS, Gao N. Trans. Nonferrous Met. Soc. China 2011;21:1199-209.

[80] Starink M. Thermochim Acta 2003;404:163-76. 
[81] Panseri C, Federighi T. Acta Metall. 1963;11:575-84.

[82] Salazar-Guapuriche MA, Zhao YY, Pitman A, Greene A. Correlation of strength with hardness and electrical conductivity for aluminium Alloy 7010. Vancouver; 2006.

[83] Ashby MF. Philos. Mag. 1966;14:1157-78.

[84] Starink MJ, Wang P, Sinclair I, Gregson PJ. Acta Mater. 1999;47:3855-68.

[85] Ashby MF. Strengthening Methods in Crystals 1971:137-92.

[86] Starink MJ, Wang SC. Acta Mater. 2003;51:5131-50.

[87] Li X, Xiong B, Zhang Y, Hua C, Wang F, Zhu B, Liu H. Sci China Ser E Technol Sci 2009;52:67-71.

[88] Starink MJ, van Mourik P. Mater. Sci. Eng. A 1992;156:183-94.

[89] Berg L, Gjønnes J, Hansen V, Li X, Knutson-Wedel M, Waterloo G, Schryvers D et al. Acta Mater. 2001;49:3443-51.

[90] Landolt-Börnstein. Thermodynamic Properties · Ternary Alloy Systems: Springer-Verlag; 2005.

[91] Rothman SJ, Peterson NL, Nowicki LJ, Robinson LC. phys. stat. sol. (b) 1974;63:K29.

[92] Fujikawa S. Tracer diffusion of magnesium in Pseudo-Binary Al-Mg2Si alloys, in: Defect and Diffusion Forum 143-147; 1997. p. 403-408.

[93] Fries SG, Jantzen T. Thermochim Acta 1998;314:23-33.

[94] Starink MJ, Cao LF, Rometsch PA. Acta Mater. 2012;60:4194-207.

[95] Clausen B, Lorentzen T, Leffers T. Acta Mater. 1998;46:3087-98.

[96] Qiao XG, Starink MJ, Gao N. Acta Mater. 2010;58:3690-700.

[97] Belov NA, Eskin DG, Aksenov AA. Multicomponent phase diagrams. 1st ed. Amsterdam, Boston: Elsevier; 2005.

[98] Wang SC, Starink MJ. Acta Mater. 2007;55:933-41.

[99] Yaws CL. Density of Solid - Inorganic Compounds, in: Carl L. Yaws (Ed.). Thermophysical Properties of Chemicals and Hydrocarbons. Oxford: Elsevier; 2014. p. 353-365.

[100] Martin JW, Doherty RD, Cantor B. Stability of microstructure in metallic systems. 2nd ed. Cambridge, New York, NY, USA: Cambridge University Press; 1997.

[101] Xu DK, Rometsch PA, Birbilis N. Mater. Sci. Eng. A 2012;534:244-52.

[102] Liang H, Chen S, Chang YA. Metall. Mater. Trans. A-Phys. Metall. Mater. Sci. 1997;28:1725-34.

[103] Cheong S, Weiland H. Understanding a microstructure using GOS (Grain Orientation Spread) and its application to recrystallization study of hot deformed Al-Cu-Mg alloys; 2007.

[104] Conserva M, Leoni M. Metall Trans 1975;6:189-95.

[105] Tsivoulas D, Robson JD, Sigli C, Prangnell PB. Acta Mater. 2012;60:5245-59.

[106] Liu SD, Zhang XM, Chen MA, You JH. Mater Charact 2008;59:53-60.

[107] Lim ST, Yun SJ, Nam SW. Mater. Sci. Eng. A 2004;371:82-90.

[108] Hatch JE. Aluminum. Metals Park, Ohio: American Society for Metals; 1984.

[109] Mondolfo LF. Aluminium Alloys: Structure and Properties; 1976.

[110] Eivani AR, Ahmed H, Zhou J, Duszczyk J, Kwakernaak C. Mater. Sci. Technol. 2011;27:1294-8. 